\title{
Explaining trends and patterns in attitudes towards wife-beating among women in Nigeria: analysis of 2003, 2008, and 2013 Demographic and Health Survey data
}

Correspondence:

kboyediran@gmail.com

John Snow Inc/MEASURE Evaluation Project, Suite 16, 1616 N. Fort Myer Drive, Arlington, VA 22209, USA

\begin{abstract}
This paper examines the patterns and trends in attitudes towards wife-beating among women in Nigeria and their determinants. Using the Nigeria Demographic and Health Survey datasets, a multivariate logistic regression was fitted to assess the relationships between sociocultural factors and a woman's attitude towards being beaten by her spouse. The results indicate a significant change over time in the percentage of Nigerian women supporting or accepting the notion that a man is justified in beating or hitting his wife. The findings show that during interviews in 2003,2008 , and $2013,62.4,45.7$, and $37.1 \%$ of women, respectively, believed that wife-beating was justified for at least one of the reasons given. Education, place of residence, wealth index, ethnic affiliation, religious affiliation, women's autonomy in household decision-making, and frequency of listening to the radio were significantly related to acceptance of wife-beating over the years. The study underscores the importance of these factors to the development of policies addressing gender-based violence and urges special attention and intervention to mitigate the effect of the cultural practices that underlie domestic violence against women in Nigeria.
\end{abstract}

Keywords: Women, Domestic violence, Attitudes, Autonomy, Husband, Wife, Trend, Nigeria

\section{Introduction}

Domestic violence affects millions of people globally, especially women and girls in both developed and developing countries. Domestic violence has been linked to poor health outcomes among women, such as acute morbidity (Campbell 2002), physical injuries (Heise 1993; Krug et al. 2002; Garcia-Moreno et al. 2006), gynecological problems (Mayhew and Watts 2002), sexually transmitted infections (Krug et al. 2002; Silverman et al. 2008), and depression (Heise 1993). Since the International Conference on Population and Development held in Cairo, Egypt (1994), and at the Fourth World Conference on Women held in Beijing (United Nations 1995), public discourse on domestic violence against women has increased, along with interest in programmatic interventions and research among policymakers, donors, program managers, and researchers. The platforms of actions ensuing from these conferences highlighted the paucity of data on the global

(c) The Author(s). 2016 Open Access This article is distributed under the terms of the Creative Commons Attribution 4.0 International License (http://creativecommons.org/licenses/by/4.0/), which permits unrestricted use, distribution, and reproduction in any medium, provided you give appropriate credit to the original author(s) and the source, provide a link to the Creative Commons license, and indicate if changes were made. 
prevalence, nature, causes, and consequences of domestic violence. This absence of data has restricted understanding of the magnitude and seriousness of this issue, which affects the development of effective approaches and strategies to stem the problem.

However, a number of scholars have investigated and documented the prevalence of and factors associated with domestic violence against women in many parts of the globe (Kishor and Johnson 2004; Kimani 2007; Hindin et al. 2008; Owoaje and OlaOlorun 2012; Tenkorang et al. 2013; Solanke 2014). These studies examined physical, sexual, and psychological violence perpetrated by intimate male partners. A multi-country analysis of Demographic and Health Survey (DHS) data showed that approximately one fifth to one half of women experienced spousal or intimate-partner abuse (Kishor and Johnson 2004). Several scholars have reported on the widespread domestic violence perpetrated against Arab women by their spouses (Douki et al. 2003; Khawaja and Twetel-Salem 2004; Khawaja and Barazi 2005; Diop-Sidibe et al. 2006; Usta et al. 2007). Domestic violence against women is also prevalent in Asia, Europe, and South America (Ellsberg et al. 1999; Burazeri et al. 2005; Khan and Aeron 2006).

Domestic violence is also pervasive in sub-Saharan Africa (Koenig et al. 2003; Kimani 2007; Tenkorang et al. 2013; Oyediran and Cunningham 2014; Solanke 2014; Wekwete et al. 2014) due to cultural values and norms that condone and reinforce abusive practices against women (Kim and Motsei 2002; Tenkorang et al. 2013). For instance, in Zimbabwe, about half of married women experience some form of gender-based violence (Wekwete et al. 2014), and $15.6 \%$ of women in Nigeria report having experienced physical violence (Solanke 2014).

Despite growing interest in this issue, most studies on domestic violence have been limited to its prevalence, causes, and consequences. A few studies (Hindin 2003; Oyediran and Isiugo-Abanihe 2005; Khawaja et al. 2008; Linos et al. 2010) explored attitudinal perspectives; yet further data are needed. Developing a policy and program framework to prevent intimate-partner or domestic violence requires reliable data on the social context of wife-beating, particularly in patriarchal cultures where women have always been subjugated.

The patriarchal culture widespread across sub-Saharan Africa is the bedrock of male dominance that indirectly supports the social acceptance of wife-beating because of the subordinate societal position of women. Within a marriage, in the Nigerian tradition, it is the man who heads the household, the woman who obeys him. In this tradition, violence may be seen as a tool that a man uses to chastise his wife and to correct her mistakes or misdeeds. Despite the widespread societal practice of wife-beating in the developing world, including sub-Saharan Africa, there are still few data on the prevalence, causes, or predictors of acceptance of wife-beating (Hindin 2003; Lawoko 2006). Existing literature on wife-beating in sub-Saharan African countries, including Nigeria, has focused extensively on its actual prevalence and determinants (Diop-Sidibe et al. 2006; Ilika et al. 2002; Koenig et al. 2003; Odujinrin 1993; Okemgbo et al. 2002) and less on the underlying attitudes towards wife-beating. Also, despite the availability of a domestic-violence module in the DHS, with several waves conducted in most countries, no study has examined trends and changes in attitudes towards wife-beating.

In the Nigerian context, scholars have documented a high prevalence of wife-beating. Also, several studies have examined attitudes towards wife-beating and reveal a high prevalence of support for wife-beating among men and women (Ogunjuyigbe et al. 
2005; Oyediran and Isiugo-Abanihe 2005; Oyedokun 2007). However, there has been limited examination of trends in the magnitude of wife-beating or factors associated with acceptance of wife-beating among men and women.

Literature from sub-Saharan Africa indicates that although gender-based violence still persists, it seems to be diminishing, either due to increasing advocacy by development program or because of activities emphasizing the attitudinal changes of women. For instance, Pierotti (2013) demonstrated that during the first decades of the millennium, an increasing proportion of women in many sub-Saharan African countries rejected the idea that husbands were justified in beating their wives for any reason. Pierotti gives an example from Ghana, where the proportion of women who rejected justifications for domestic violence decreased from 61.5\% in 2003 to 50.5\% in 2008 (Pierotti 2013).

Abundant evidence suggests that norms, values, and attitudes are changing globally in ways that should help reduce wife-battering in the future. In Nigeria specifically, there are initiatives at both national and state levels through policies, laws, and legislation to make domestic violence against women socially and culturally unacceptable.

The Nigeria DHS (NDHS) of 2003, 2008, and 2013 present an opportunity to examine emerging trends and patterns in attitudes towards gender norms, using attitudes towards wife-beating as an indicator. This study examines the effect of the personal attributes of Nigerian women-including their social, economic, and demographic characteristics-on their attitudes towards wife-beating. The study also explores patterns of geographic variability in attitudes towards wife-beating across the country.

\section{Theoretical framework and study hypotheses}

Most studies show that collectively, patriarchal societies expect women to play certain conventional roles, such as birthing and caring for children, taking care of the house, being subservient to their spouses, and submitting to their husbands' sexual needs (Hindin 2003; Oyediran and Isiugo-Abanihe 2005; Rani et al. 2004; Lawoko 2006; Lawoko 2008). In male-controlled cultures, changes in what women demand of their sexual partners by the women are cited as a key reason for marital violence (Watts and Mayhew 2004). This study builds on the work of Rani et al. (2004), in assuming in patriarchal societies, transgression on gender roles is seen by both men and women as a justifying condition for violence.

The social learning theory and the socio-ecological model provide the conceptual framework for explaining women's perceived attitude of justifying wife-beating. This theory posits that people observe and model others' behaviors, attitudes, and emotional reactions, particularly those of significant others at home, school, and community levels. Social values, norms, and gender roles in a patriarchal society are conveyed within social groups and diffused from generation to generation. Acceptance of wife-beating is premised on the patriarchal norm of male domination. The effects of changes and adoption of foreign values can alter the social learning process by encouraging individuals (including women) to challenge established social values and question those that cause harm/are no longer acceptable. Rani and colleagues posit that these enabling factors will work through three mechanisms by (1) producing a conflict between reality and the myth of male dominance, (2) exposing to more egalitarian social networks and social structures other than kinship, and (3) exposing communities to modern norms and values through the media (Rani et al. 2004). 
Many Nigerian societies maintain rigid gender norms. Many social practices, such as uneven distribution of power in marital relations, polygamy, acceptance of male promiscuity, power of extended family over married couples, restriction of women's mobility, and the almost universal prevalence of bride wealth, explain the persistence of male superiority and widespread violence against women in Nigerian culture.

Other factors may moderate or influence cultural support for marital violence in Nigeria. Enabling factors-increased access to education, employment in the formal sector, participation in public roles, including the political sphere, and improved fiscal responsibility within the household-may lead women to challenge or question social norms about gender roles. Both education and urbanization may increase the likelihood of women having non-supportive attitude towards wife-beating over time.

However, multi-level factors (at the individual, micro, exo, and macro levels) reinforce cultural norms that condone violent punishment of wives. At the individual level, limitations in education and access to employment represent disabling factors for women. At the micro (household) level, women's lack of autonomy to make decisions about household purchases can put them at risk. Also, exposure to violence within the family and acceptance of wife-beating to resolve conflicts may perpetuate acceptance of such violence-even if enabling factors are present. For instance, if a woman increases her financial contributions to household expenses, the chance of conflict may increase, because these contributions could diminish men's authority. Yet men who contribute the bulk of household income would be uninhibited about violence, because they hold fiscal dominance. Similarly, high female autonomy as measured by women's participation in household decision-making should be associated with reduced acceptance of spouse-beating.

Interlinked factors at the exo level also underpin marital violence. The broader social, political, and economic environment (such as the limited availability of legal redress for battered women and women's related failure to seek such support) reinforce violence at home. Exo factors also influence the structure and availability of microsystems that can influence the spousal relationship. Finally, normative social values (macro factors) are subject to social, political, and economic conditions (Bukatko and Daehler 2001) that can influence women's perceptions of wife-beating. Spousal age and differences between spouses' respective ages can also affect the gender power balance, in that an individual performs unique social roles at specific ages.

The multiple influences mentioned above suggest two study hypotheses about the effects of social learning and socio-ecological models on women's attitudes towards wifebeating: (1) women who are more educated and who are urban dwellers will have lower odds of reporting that wife-beating is justified and (2) women who belong to ethnic groups or religions with more conservative values, or who live in regions dominated by such groups, or that are populated by groups tending to condone domestic violence, will have higher odds of reporting that wife-beating is justified.

\section{Data and methods}

\section{Study design and data}

The present study used data from the Nigeria Demographic and Health Surveys or NDHS: nationally representative sample surveys conducted in 2003, 2008, and 2013. The National Population Commission of Nigeria collected these data with technical assistance 
from Macro International as part of activities funded by the US Agency for International Development through the MEASURE DHS+ project. The surveys are designed to collect, analyze, and disseminate data about maternal health, sexual and reproductive health, and malaria among women aged 15 to 49, along with information on the demographic, social, and economic characteristics of these women and members of their households. The NDHS also examines attitudes towards gender roles, exposure to messages about health care in the media, and knowledge of and attitudes towards the use of reproductive health services.

The NHDS took nationally representative samples of women, covering both rural and urban households using stratified and multistage cluster sample designs. To examine trends in, prevalence of, and factors associated with acceptance of wife-beating, the analytic samples considered both ever-married and single women. The three survey datasets primarily contain individual sampling weights for women, which were obtained by further correction for women's individual nonresponse based on household sampling weights (National Population Commission (Nigeria) and ICF International, 2014). The datasets were pooled and thus comprised 7620 respondents from the 2003 NDHS, 33,385 respondents from the 2008 NDHS, and 38,948 respondents for the 2013 NDHS.

\section{Dependent variable}

The NDHS collects data on women's attitudes towards wife-beating through hypothetical questions about violence that could take place when a husband becomes angered by things that his wife does. The respondents were asked whether a husband would be justified for hitting or beating his wife in the following situations: (a) she goes out without telling him, (b) she neglects the children, (c) she argues with him, (d) she refuses to have sex with him, and (e) she burns food during cooking. A binary variable (yes/no) was created for each question. All "don't know" responses, comprising between 2 and $5 \%$, were treated as missing values.

From these dichotomous (yes/no) variables, an index representing respondents' attitudes towards wife-beating was created, with a score range of $0-5$. The index places individual women on a continuous scale of relative acceptance of the husbands' right to beat his wife in at least one of the five scenarios. The index was then categorized into a binary variable as women who does not support husband beating their spouse under any circumstances and those who support wife-beating for at least one reason. A binary outcome variable was created for acceptance of wife-beating, coded as " 0 " if the respondent did not agree that a husband is justified in beating his wife in any of the situations and coded as " 1 " if the respondent agreed in at least one situation. A logistic regression model was used to examine the effects of selected demographic and socioeconomic variables on women's attitudes towards wife-beating (as the outcome variable).

\section{Independent variables}

The independent variables, then, were the following: (a) age, (b) marital status, (c) educational status, (d) religion, (e) women's autonomy in household decision-making, (f) wealth index, (g) number of living children, (h) place of residence, (i) region of residence, ( $\mathrm{j}$ ) exposure to media, ( $\mathrm{k}$ ) ethnic affiliation, and (l) spousal age difference. The inclusion of the covariates was informed by previous studies on factors associated with acceptance of wife-beating, especially in the context of sub-Saharan Africa (Hindin 
2003; Rani et al. 2004; Ogunjuyigbe et al. 2005; Oyediran and Isiugo-Abanihe 2005; Lawoko 2006; Oyedokun 2007; Uthman et al. 2009).

\section{Statistical analysis}

Exploratory data analysis was conducted on all variables of interest using percentages and means. Thereafter, bivariate analysis was conducted using a chi-square test to assess the associations between the outcome variable and the independent variables within and across the three survey years. All the independent variables, including survey year, were further subjected to multivariate analysis, using a pooled dataset for each year examined to identify the significant determinants of acceptance of wife-beating while controlling for the extraneous influence of the survey years. A logistic regression model was used to determine the net effect of explanatory variables on women's acceptance of wife-beating. All analyses were conducted on weighted data (women had individual sampling weights in NDHS).

First, trends and percentage changes between survey waves were computed for women reporting that husbands are justified in beating their wives, specifically for the nevermarried and ever-married categories, by age and education level. Attempts were made to further investigate regional patterns by computing and mapping percentages and percentage changes for each category (single and never-married) using 2003 and 2013 data. This provided an exploratory analysis of the changes that occurred between 2003 and 2013.

Next, a binary logistic regression model was fitted by combining all data between 2003 and 2013 for the multivariate analysis to obtain an odds ratio with a $p$ value less than or equal to 0.05 considered significant. In all models, the current age of the woman and her total number of living children were estimated as continuous variables, while region, education, religion, wealth index, exposure to media (radio and television), and residence (urban versus rural) were estimated as categorical independent variables. A maximum estimation of likelihood was applied. All models were fitted in STATA version 12.0 .

\section{Results}

\section{Profile of the study population}

Table 1 presents information about the study population. Generally, across the three survey years, about three fifths of the study population were aged 25-49 years, with an average age of about 29 years, except in 2003 when the average was 28.02 years. Almost seven out of 10 were currently married or cohabiting; about $60 \%$ had had any formal education; and at least 50\% were Christians.

About two thirds of the study population were currently in a monogamous union. Over half of women reported being involved in household decision-making in 2003 and 2008 , though this proportion decreased dramatically to $37.8 \%$ in 2013: a surprising finding, given expectations of improvements across the continuum of women's empowerment, but possibly due to continuing adherence to conservative values. About two fifths of the women resided in households categorized in the lower two quintiles of the wealth index; nearly two fifths had three or more living children. Nearly two thirds of respondents lived in rural areas, and more than half resided in the northern regions 
Table 1 Respondents' distribution according to demographic and socioeconomic characteristics, 2003-2013 NDHS

\begin{tabular}{|c|c|c|c|c|c|c|c|c|c|}
\hline \multirow[t]{3}{*}{ Characteristics } & \multicolumn{9}{|c|}{ Percentage } \\
\hline & \multicolumn{3}{|l|}{2003} & \multicolumn{3}{|l|}{2008} & \multicolumn{3}{|l|}{2013} \\
\hline & $\begin{array}{l}\text { Ever- } \\
\text { married }\end{array}$ & $\begin{array}{l}\text { Never- } \\
\text { married }\end{array}$ & All & $\begin{array}{l}\text { Ever- } \\
\text { married }\end{array}$ & $\begin{array}{l}\text { Never- } \\
\text { married }\end{array}$ & All & $\begin{array}{l}\text { Ever- } \\
\text { married }\end{array}$ & $\begin{array}{l}\text { Never- } \\
\text { married }\end{array}$ & All \\
\hline \multicolumn{10}{|l|}{ Type of marital union } \\
\hline Monogamous & 64.1 & NA & 64.1 & 65.3 & NA & 65.3 & 66.4 & NA & 66.5 \\
\hline Polygamous & 35.9 & & 35.9 & 34.7 & & 34.7 & 33.6 & & 33.5 \\
\hline \multicolumn{10}{|l|}{ Age } \\
\hline $15-24$ & 24.9 & 88.0 & 42.2 & 23.5 & 84.1 & 38.0 & 22.1 & 83.4 & 37.5 \\
\hline $25-34$ & 37.4 & 10.8 & 30.1 & 38.3 & 14.2 & 32.5 & 37.7 & 14.6 & 31.9 \\
\hline 35 years and above & 37.7 & 1.2 & 27.7 & 38.2 & 1.7 & 29.5 & 40.2 & 2.1 & 30.6 \\
\hline Mean age & 31.2 & 19.6 & 28.0 & 31.4 & 19.9 & 28.6 & 31.9 & 19.9 & 28.9 \\
\hline \multicolumn{10}{|l|}{ Spousal age difference } \\
\hline Less than 5 years & 14.7 & & 14.7 & 17.7 & & 17.7 & 18.5 & & 18.5 \\
\hline $5-9$ years & 32.6 & NA & 32.6 & 33.6 & & 33.6 & 33.8 & NA & 33.8 \\
\hline $10-14$ years & 26.1 & & 26.1 & 24.9 & NA & 24.9 & 24.0 & & 24.0 \\
\hline 15 years and above & 26.6 & & 26.1 & 23.9 & & 23.9 & 23.8 & & 23.8 \\
\hline $\begin{array}{l}\text { Mean age difference } \\
\text { between spouses }\end{array}$ & 11.3 & NA & 11.3 & 10.5 & NA & 10.5 & 10.9 & NA & 10.9 \\
\hline \multicolumn{10}{|c|}{ Highest level of education } \\
\hline None & 51.9 & 6.5 & 39.4 & 50.5 & 5.3 & 39.7 & 45.0 & 6.6 & 35.3 \\
\hline Primary & 22.9 & 19.1 & 21.9 & 22.0 & 12.6 & 19.7 & 21.1 & 9.8 & 18.2 \\
\hline Secondary & 20.1 & 64.7 & 32.3 & 21.2 & 69.0 & 32.7 & 26.2 & 69.1 & 37.0 \\
\hline Post-secondary & 5.1 & 9.7 & 6.4 & 6.3 & 13.1 & 7.9 & 7.8 & 14.6 & 9.5 \\
\hline \multicolumn{10}{|l|}{ Wealth quintile } \\
\hline First & 22.3 & 11.8 & 19.4 & 25.9 & 9.0 & 21.8 & 20.8 & 5.5 & 17.0 \\
\hline Second & 20.3 & 13.1 & 18.4 & 22.6 & 13.5 & 20.4 & 21.6 & 12.4 & 19.3 \\
\hline Third & 19.8 & 19.7 & 19.8 & 19.2 & 21.2 & 19.7 & 19.8 & 22.7 & 20.5 \\
\hline Fourth & 19.0 & 23.5 & 20.3 & 17.1 & 27.7 & 19.6 & 19.5 & 28.3 & 21.7 \\
\hline Fifth & 18.5 & 31.8 & 22.2 & 15.2 & 28.6 & 18.4 & 18.3 & 31.1 & 21.5 \\
\hline \multicolumn{10}{|l|}{ Place of residence } \\
\hline Urban & 37.1 & 48.1 & 40.1 & 27.8 & 43.0 & 31.4 & 35.2 & 53.8 & 39.9 \\
\hline Rural & 62.9 & 51.9 & 59.9 & 72.2 & 57.0 & 68.6 & 64.8 & 46.2 & 60.1 \\
\hline \multicolumn{10}{|l|}{ Geopolitical zone } \\
\hline North-Central & 16.6 & 16.2 & 16.5 & 18.7 & 20.1 & 19.1 & 15.3 & 18.1 & 16.1 \\
\hline Northeast & 21.9 & 9.6 & 18.5 & 21.2 & 10.5 & 18.6 & 19.2 & 10.5 & 17.0 \\
\hline Northwest & 29.4 & 8.0 & 23.5 & 26.7 & 6.6 & 21.9 & 29.6 & 10.8 & 24.8 \\
\hline Southeast & 10.2 & 24.8 & 14.2 & 8.6 & 18.6 & 11.0 & 9.2 & 18.2 & 11.5 \\
\hline South-South & 9.7 & 19.4 & 12.3 & 11.7 & 23.2 & 14.4 & 12.8 & 23.9 & 15.6 \\
\hline Southwest & 12.3 & 22.0 & 15.0 & 13.2 & 20.8 & 15.1 & 13.9 & 18.5 & 15.1 \\
\hline \multicolumn{10}{|l|}{ Region of residence } \\
\hline Northern & 67.8 & 33.8 & 58.5 & 66.6 & 37.4 & 59.5 & 64.1 & 39.4 & 57.9 \\
\hline Southern & 32.2 & 66.2 & 41.5 & 33.4 & 62.6 & 40.5 & 35.9 & 60.6 & 42.1 \\
\hline \multicolumn{10}{|l|}{ Religious affiliation } \\
\hline Catholic & 11.8 & 24.4 & 15.3 & 8.9 & 16.4 & 10.7 & 8.6 & 16.2 & 10.5 \\
\hline
\end{tabular}


Table 1 Respondents' distribution according to demographic and socioeconomic characteristics, 2003-2013 NDHS (Continued)

\begin{tabular}{|c|c|c|c|c|c|c|c|c|c|}
\hline Other Christians & 29.4 & 52.7 & 35.8 & 34.1 & 61.6 & 40.7 & 34.9 & 57.0 & 40.5 \\
\hline Muslim & 56.7 & 22.3 & 47.1 & 54.3 & 21.0 & 46.3 & 55.0 & 26.0 & 47.7 \\
\hline Others & 2.2 & 0.6 & 1.7 & 2.7 & 1.1 & 2.3 & 1.6 & 0.8 & 1.4 \\
\hline \multicolumn{10}{|l|}{ Number of living children } \\
\hline None & 11.8 & 94.5 & 34.5 & 10.2 & 93.2 & 30.1 & 9.6 & 93.0 & 30.6 \\
\hline 1-2 children & 32.4 & 5.4 & 25.0 & 31.1 & 6.5 & 25.1 & 30.7 & 6.7 & 24.6 \\
\hline 3-4 children & 26.9 & 0.1 & 19.5 & 29.9 & 0.3 & 22.8 & 29.6 & 0.3 & 22.3 \\
\hline 5 children and above & 28.9 & 0.1 & 21.0 & 28.9 & 0.1 & 22.0 & 30.1 & 0.1 & 22.5 \\
\hline \multicolumn{10}{|c|}{ Women's autonomy (decision-making process) } \\
\hline Participated or involved & 63.9 & 30.9 & 54.9 & 57.0 & 0.0 & 56.7 & 50.5 & 0.0 & 37.8 \\
\hline $\begin{array}{l}\text { Not participated or } \\
\text { involved }\end{array}$ & 36.1 & 69.1 & 45.1 & 43.0 & 100.0 & 43.3 & 49.5 & 100.00 & 62.2 \\
\hline \multicolumn{10}{|l|}{ Ethnic affiliation } \\
\hline Hausa/Fulani & 37.6 & 7.0 & 29.1 & 35.5 & 6.9 & 28.6 & 36.5 & 12.0 & 30.3 \\
\hline Igbo & 13.6 & 30.5 & 18.2 & 10.8 & 23.1 & 13.7 & 11.4 & 21.9 & 14.0 \\
\hline Yoruba & 11.4 & 19.6 & 13.7 & 12.8 & 20.7 & 14.7 & 13.3 & 18.9 & 14.7 \\
\hline Northern minorities & 21.3 & 17.3 & 20.2 & 27.9 & 26.9 & 26.7 & 25.2 & 23.3 & 24.7 \\
\hline Southern minorities & 6.0 & 12.5 & 7.8 & 10.5 & 20.7 & 13.0 & 12.6 & 22.8 & 15.1 \\
\hline $\begin{array}{l}\text { Others including } \\
\text { foreigners }\end{array}$ & 10.1 & 13.2 & 11.0 & 2.6 & 1.7 & 2.4 & 1.1 & 1.1 & 1.1 \\
\hline \multicolumn{10}{|c|}{ Frequency of listening to radio } \\
\hline $\begin{array}{l}\text { Never or less than once } \\
\text { a week }\end{array}$ & 44.3 & 36.9 & 42.3 & 53.0 & 38.9 & 49.6 & 63.6 & 54.0 & 61.2 \\
\hline At least once a week & 55.7 & 63.1 & 57.7 & 47.0 & 61.1 & 50.4 & 36.4 & 46.0 & 38.8 \\
\hline \multicolumn{10}{|c|}{ Frequency of watching television } \\
\hline $\begin{array}{l}\text { Never or less than once } \\
\text { a week }\end{array}$ & 72.3 & 48.3 & 65.7 & 71.1 & 44.2 & 64.6 & 69.3 & 49.0 & 64.2 \\
\hline At least once a week & 27.7 & 51.7 & 34.3 & 28.9 & 55.8 & 35.4 & 30.7 & 51.0 & 35.8 \\
\hline \multicolumn{10}{|c|}{ Frequency of reading newspaper or magazine } \\
\hline $\begin{array}{l}\text { Never or less than once } \\
\text { a week }\end{array}$ & 91.9 & 77.3 & 87.9 & 93.1 & 79.0 & 89.7 & 93.0 & 82.9 & 90.5 \\
\hline At least once a week & 8.1 & 22.7 & 12.1 & 6.9 & 21.0 & 10.3 & 7.0 & 17.1 & 9.5 \\
\hline
\end{tabular}

of Nigeria. There was no significant variation in the distribution of respondents by background characteristic across the three surveys.

\section{Patterns and trends}

In 2003, 62.4\% of women reported believing that wife-beating would be justified for at least one of the scenarios presented in the DHS. In 2008 and 2013, 45.7 and 37.1\% of women, respectively, reported that wife-beating would be justified for at least one of the five scenarios presented during the interview. Thus, the proportion of women supporting wife-beating declined by 25.3 percentage points over the period 2003-2013. Figure 1 reveals that the proportion of women believing that wife-beating is justified for each of the five reasons declined over the 10-year period. The trends for all five scenarios are similar in that they show a sharp drop in both 2008 and 2013, except for the "burning of food" 


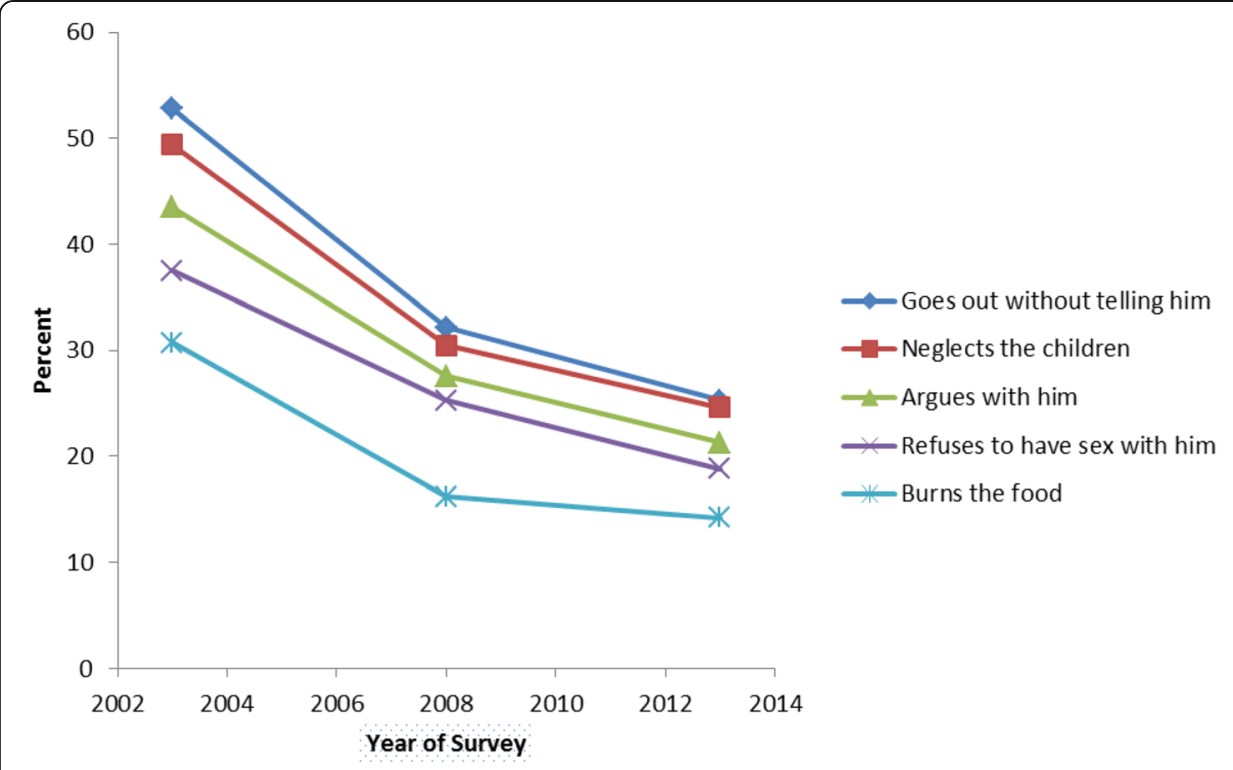

Fig. 1 Percentage of women justifying wife-beating by hypothetical reason in Nigeria from 2003 to 2013

category, which was stable between 2008 and 2013. Overall, the proportion of women reporting that wife-beating is justified for at least one of these reasons declined over time. For instance, about $24 \%$ of the women reported that wife-beating is justified for all five of the reasons in 2003, as compared with 14.1 and $11.1 \%$ in 2008 and 2013, respectively. Multivariate analysis of the trend showed that women's support for patterns of wifebeating decreased significantly in Nigeria between 2003 and 2013.

Figures 2, 3, and 4 show regional variation in support for acceptance of wife-beating among Nigerian women in 2003, 2008, and 2013, respectively, when the wife goes out without telling her husband. Higher support was observed in the Northeast region in 2003, while a lower level of support were observed in the Southeast. In 2013, the lowest levels of support for the husband's right to beat his wife if she goes out without telling him were observed in the Southwest.

In 2008, the proportion of women justifying violence against wives who argue with their husbands was similar across regions, although support was somewhat lower in the Southwest. However, the proportion of women who reported that a man is justified beating or hitting his wife if she goes out without telling him increased in 2008, compared with 2003. The patterns of women supporting wife-beating for any reason varied between 2003, 2008, and 2013 across the regions, as shown in Figs. 5, 6, and 7, respectively. Agreement that wife-beating is justified in at least one scenario is relatively low in the Southwest as compared with other regions. The percentage of women supporting a husband's right to beat or hit his wife varies by region within the 10 years under review.

Table 2 presents a bivariate analysis of women's reporting that wife-beating is justified for at least one of the five reasons in each NDHS year. The analysis is presented by current marital status, classified as ever married, never-married, and all women. (The pooled data for the three survey waves in Table 3, indicating the factors associated with the odds ratio of reporting that wife-beating is justified for ever-married, nevermarried, and all women, are based on the factors that were significant at $5 \%$ at the bivariate analysis in Table 2.) 


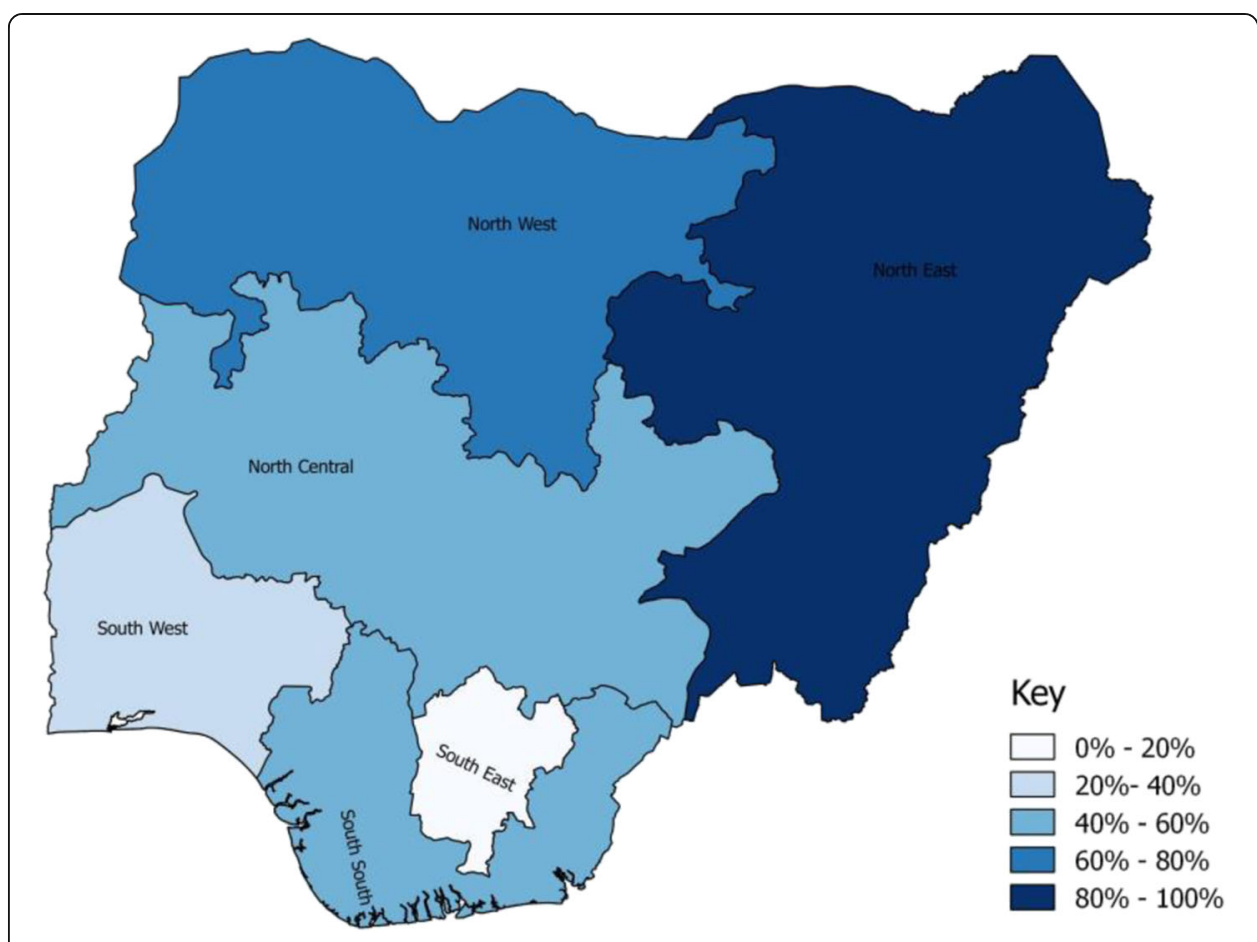

Fig. 2 Percentage of women believing that a husband is justified in beating his wife if she goes out without telling him, by region, NDHS 2003

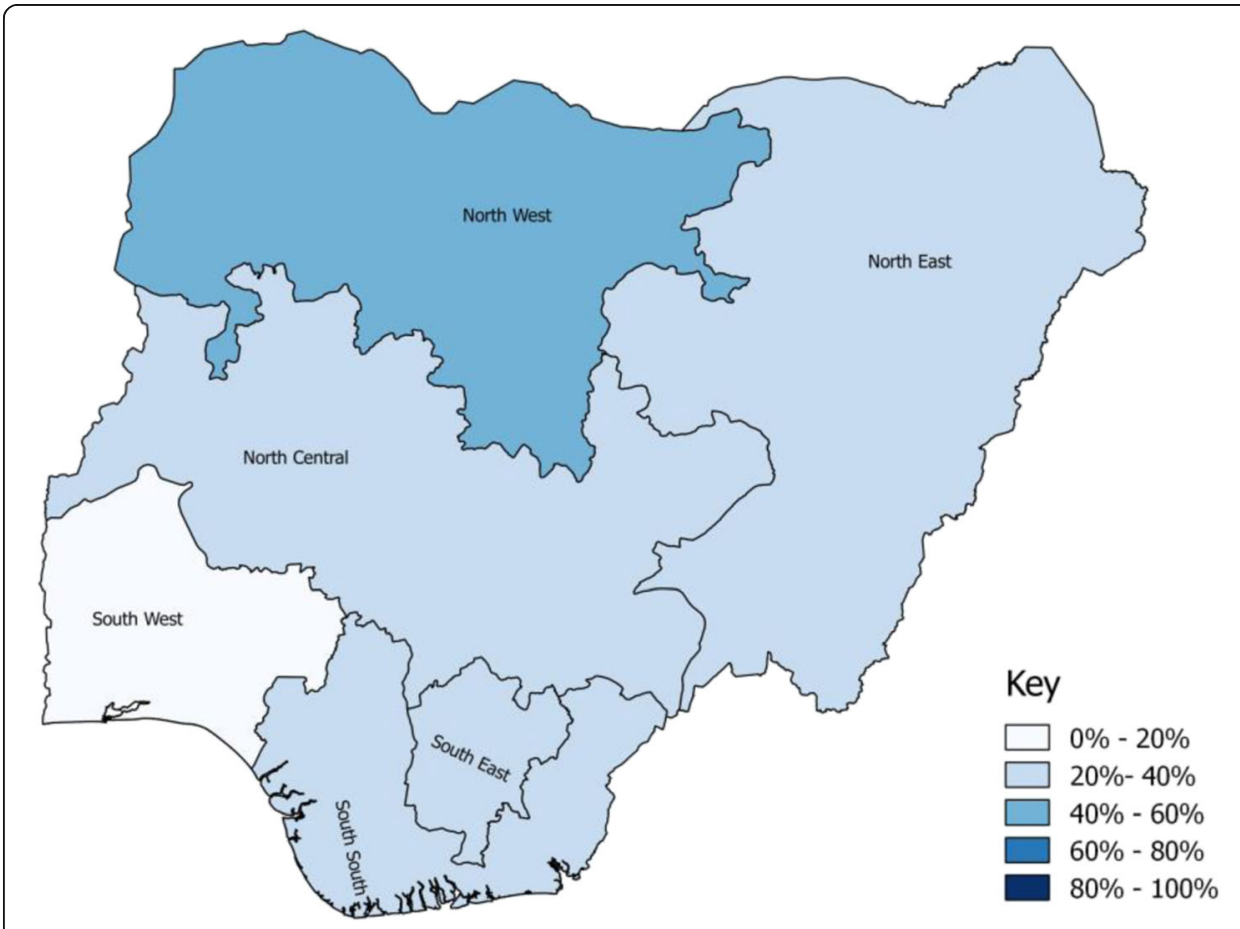

Fig. 3 Percentage of women believing that a husband is justified in beating his wife if she goes out without telling him, by region, NDHS 2008 


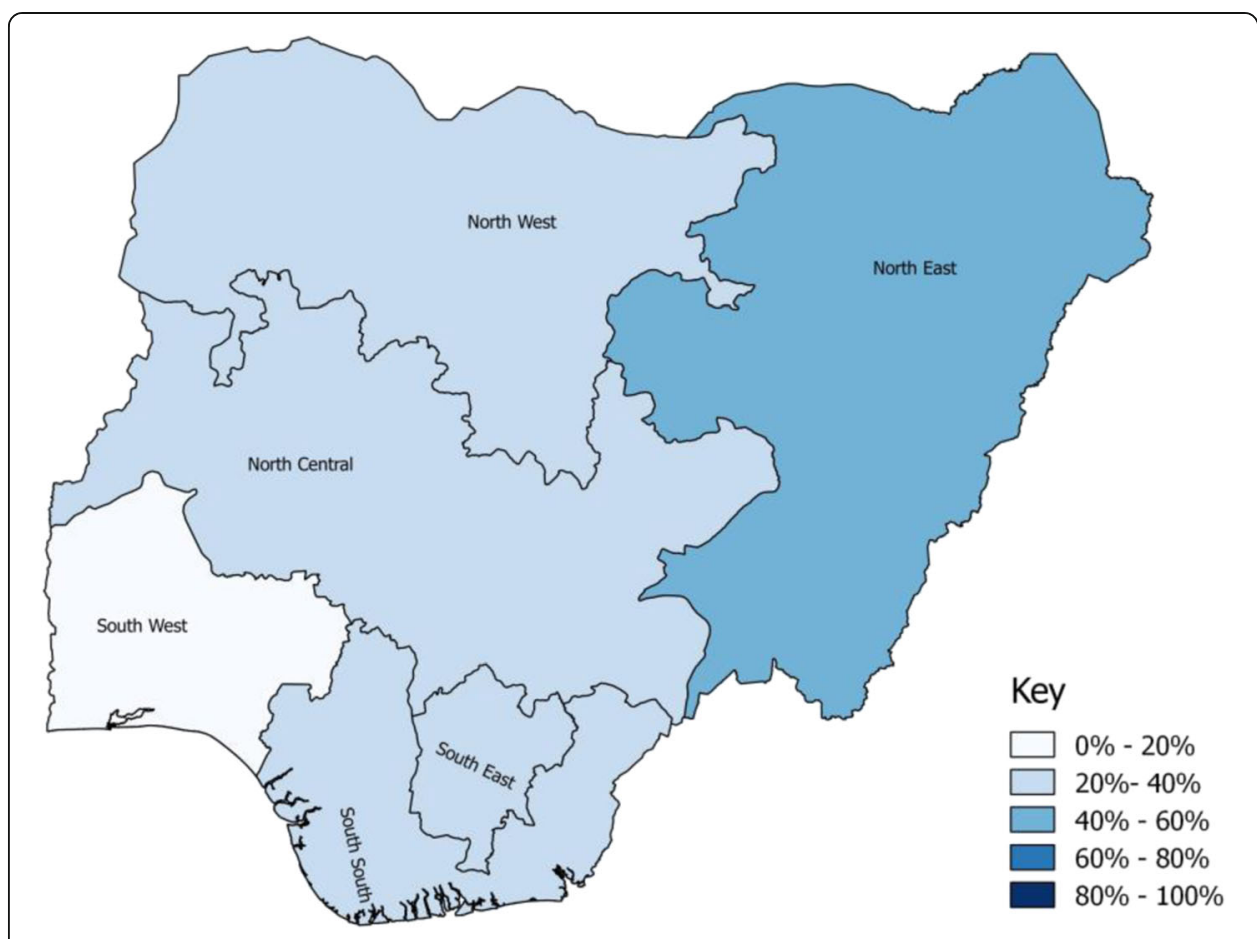

Fig. 4 Percentage of women believing that a husband is justified in beating his wife if she goes out without telling him, by region, NDHS 2013

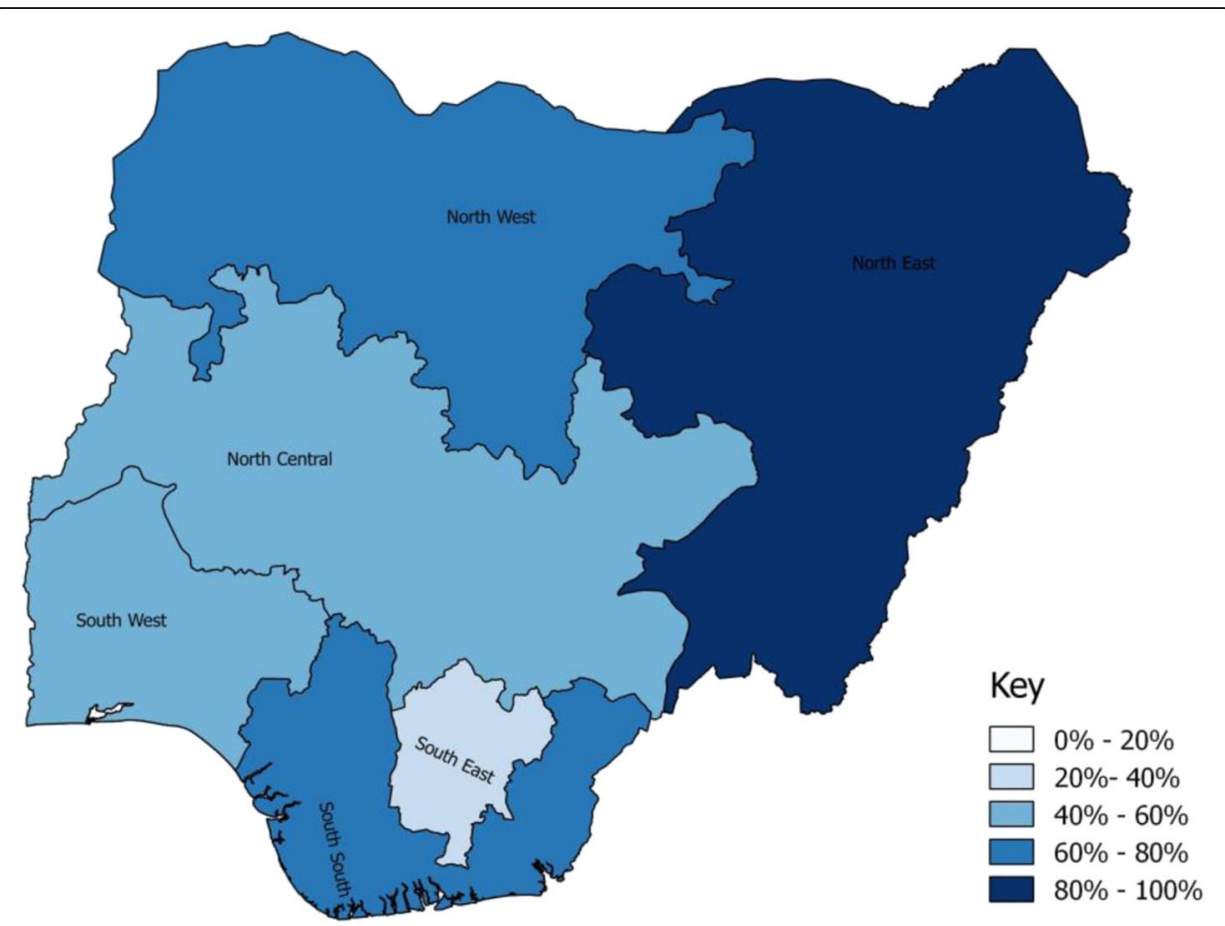

Fig. 5 Percentage of women believing that a husband is justified in beating his wife for any reason, by region, NDHS 2003 


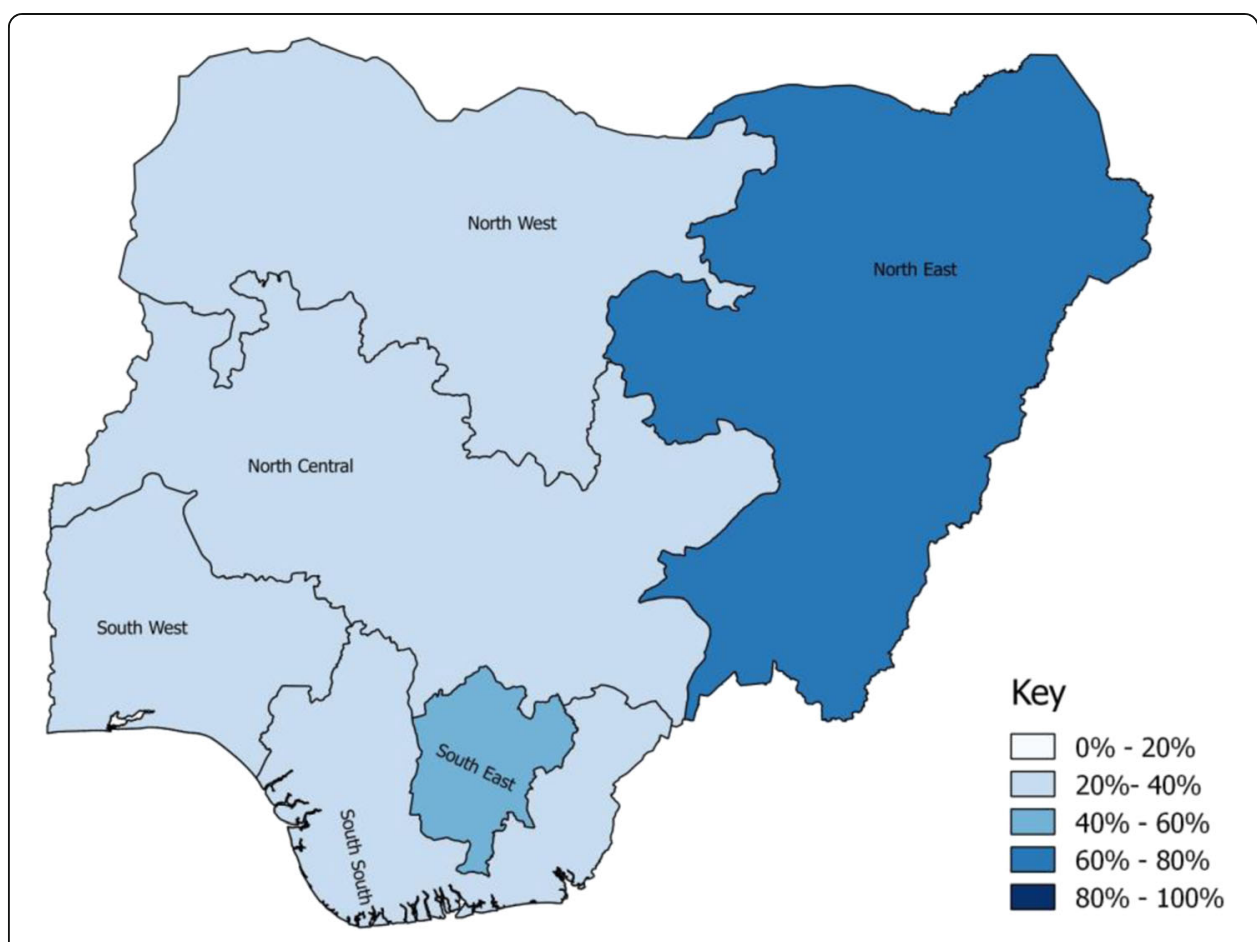

Fig. 6 Percentage of women believing that a husband is justified in beating his wife for any reason, by region, NDHS 2008

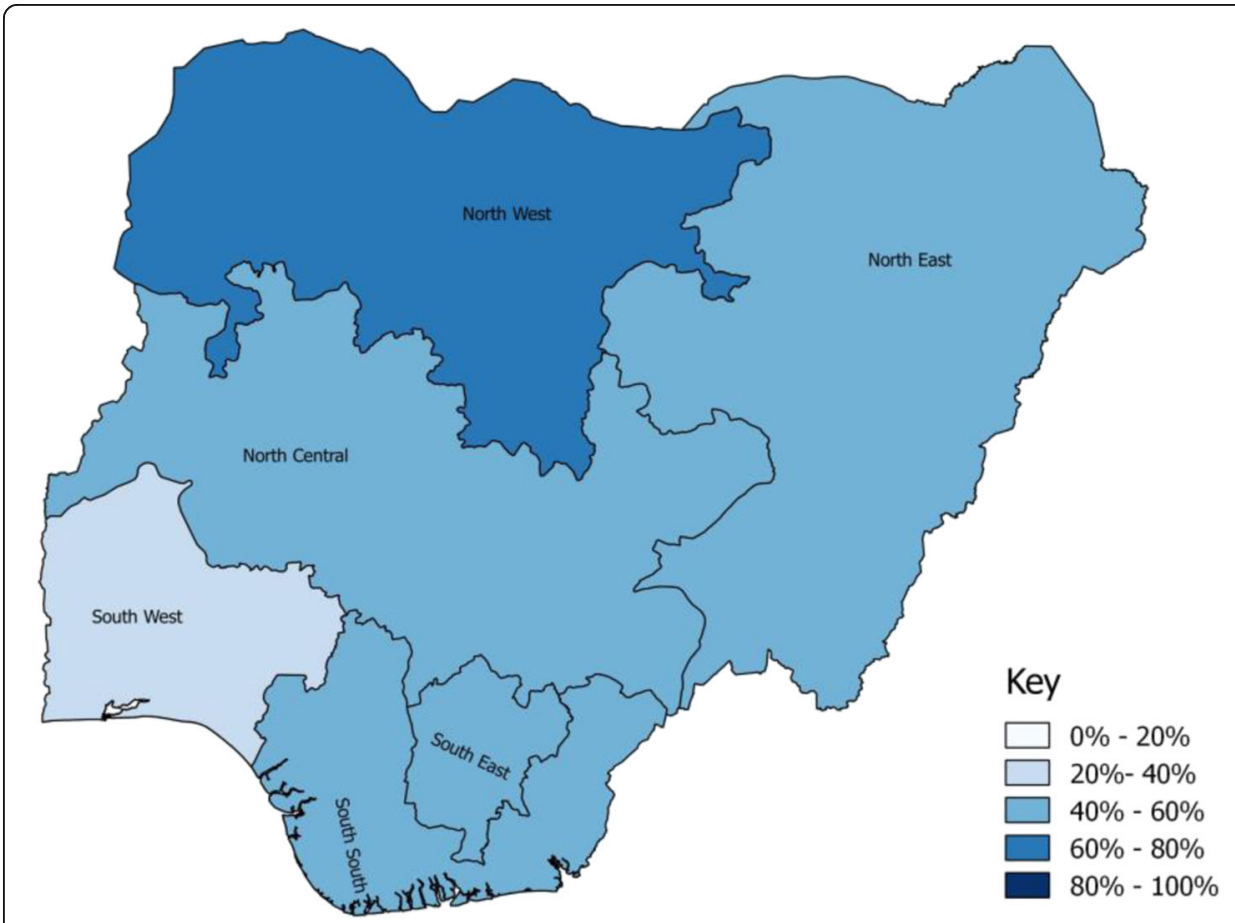

Fig. 7 Percentage of women believing that a husband is justified in beating his wife for any reason, by region, NDHS 2013 
Table 2 Percent distribution of women who agreed that a husband is justified for beating his wife by marital status according to individual characteristics, 2003, 2008, and 2013 Nigeria Demographic and Health Survey

\begin{tabular}{|c|c|c|c|c|c|c|c|c|c|}
\hline \multirow[t]{2}{*}{ Covariates } & \multicolumn{3}{|l|}{2003} & \multicolumn{3}{|l|}{2008} & \multicolumn{3}{|l|}{2013} \\
\hline & $\begin{array}{l}\text { Ever- } \\
\text { married }\end{array}$ & Single & All & $\begin{array}{l}\text { Ever- } \\
\text { married }\end{array}$ & Single & All & $\begin{array}{l}\text { Ever- } \\
\text { married }\end{array}$ & Single & All \\
\hline Total & 66.4 & 50.4 & 62.4 & 48.8 & 34.9 & 45.7 & 39.1 & 30.6 & 37.1 \\
\hline \multicolumn{10}{|l|}{$\overline{\text { Age }}$} \\
\hline $15-24$ & 73.7 & 59.0 & 65.3 & 57.4 & 45.5 & 51.1 & 46.5 & 38.2 & 41.9 \\
\hline $25-34$ & 66.2 & 39.2 & 63.5 & 49.8 & 35.0 & 48.2 & 40.5 & 30.2 & 39.3 \\
\hline $\begin{array}{l}35 \text { years and } \\
\text { above }\end{array}$ & 64.0 & 37.5 & 63.7 & 48.7 & 38.6 & 48.5 & 37.4 & 28.8 & 37.3 \\
\hline$x^{2}=$ test & $37.1^{* * *}$ & $35.8^{* * *}$ & 2.3 & $122.9^{* * *}$ & $45.3^{* * *}$ & $23.1^{* * *}$ & $143.0^{* * *}$ & $39.3^{* * *}$ & $59.3^{* * *}$ \\
\hline \multicolumn{10}{|c|}{ Spousal age difference } \\
\hline $\begin{array}{l}\text { Less than } \\
5 \text { years }\end{array}$ & 62.2 & NA & 62.2 & 45.5 & NA & 45.5 & 37.4 & NA & 37.4 \\
\hline $5-9$ years & 65.8 & & 65.8 & 49.3 & & 49.3 & 40.9 & & 40.9 \\
\hline $10-14$ years & 69.8 & & 69.8 & 53.4 & & 53.4 & 41.1 & & 41.1 \\
\hline $\begin{array}{l}15 \text { years and } \\
\text { above }\end{array}$ & 71.4 & & 71.4 & 55.2 & & 55.2 & 43.0 & & 43.0 \\
\hline$x^{2}=$ test & $24.2^{* * *}$ & & $24.2^{* * *}$ & $112.5^{* * *}$ & & $112.5^{* * *}$ & $38.1^{* * *}$ & & $38.1^{* * *}$ \\
\hline \multicolumn{10}{|c|}{ Highest level of education } \\
\hline None & 76.6 & 66.7 & 76.1 & 58.1 & 54.9 & 58.0 & 47.5 & 40.1 & 47.2 \\
\hline Primary & 66.2 & 65.4 & 66.0 & 53.7 & 56.2 & 54.0 & 42.1 & 47.7 & 42.8 \\
\hline Secondary & 52.5 & 56.7 & 54.8 & 40.1 & 44.4 & 42.3 & 33.7 & 38.1 & 35.7 \\
\hline $\begin{array}{c}\text { Post- } \\
\text { secondary }\end{array}$ & 35.1 & 31.7 & 33.7 & 23.6 & 24.9 & 24.1 & 19.5 & 22.5 & 20.7 \\
\hline$x^{2}=$ test & $358.1^{* * *}$ & $69.2^{* * *}$ & $481.7^{* * *}$ & $1000.0^{* * *}$ & $236.1^{* * *}$ & $1300.0^{* * *}$ & $837.9^{* * *}$ & $181.3^{* * *}$ & $1000.0^{* * *}$ \\
\hline \multicolumn{10}{|l|}{ Religious affiliation } \\
\hline Catholic & 53.8 & 51.6 & 52.8 & 49.8 & 50.9 & 50.2 & 44.4 & 43.5 & 44.0 \\
\hline $\begin{array}{c}\text { Other } \\
\text { Christians }\end{array}$ & 55.7 & 54.7 & 55.3 & 42.5 & 41.3 & 42.0 & 34.2 & 36.3 & 35.0 \\
\hline Muslim & 76.0 & 66.7 & 74.8 & 56.2 & 46.3 & 55.1 & 43.7 & 33.3 & 42.3 \\
\hline Others & 67.8 & 52.9 & 65.9 & 63.7 & 42.4 & 61.3 & 52.3 & 54.4 & 52.6 \\
\hline$x^{2}=$ test & $262.8^{* * *}$ & $26.1^{* * *}$ & $337.5^{* * *}$ & $444.3^{* * *}$ & $43.9^{* * *}$ & $539.7^{* * *}$ & $277.5^{* * *}$ & $55.6^{* * *}$ & $268.1^{* * *}$ \\
\hline \multicolumn{10}{|l|}{ Wealth quintile } \\
\hline First & 76.2 & 64.2 & 74.2 & 59.4 & 57.1 & 59.2 & 51.1 & 44.7 & 50.6 \\
\hline Second & 75.5 & 63.5 & 73.1 & 57.8 & 55.1 & 57.4 & 49.7 & 48.9 & 49.5 \\
\hline Third & 68.6 & 61.4 & 66.6 & 54.5 & 52.5 & 54.0 & 43.8 & 47.7 & 44.9 \\
\hline Fourth & 65.8 & 58.7 & 63.5 & 45.7 & 44.3 & 45.2 & 33.6 & 35.1 & 34.1 \\
\hline Fifth & 47.5 & 46.4 & 47.0 & 29.1 & 27.8 & 28.6 & 21.8 & 24.4 & 22.7 \\
\hline$x^{2}=$ test & $262.8^{* * *}$ & $44.1^{* * *}$ & $333.4^{* * *}$ & $1100.0^{* * *}$ & $398.5^{* * *}$ & $1600.0^{* * *}$ & $1400.0^{* * *}$ & $408.1^{* * *}$ & $1800.0^{* * *}$ \\
\hline \multicolumn{10}{|c|}{ Type of marital union } \\
\hline Monogamous & 64.0 & NA & 64.0 & 47.8 & NA & 47.8 & 38.5 & NA & 38.5 \\
\hline Polygamous & 74.0 & & 74.0 & 57.6 & & 57.6 & 45.3 & & 45.3 \\
\hline$x^{2}=$ test & $53.8^{* * *}$ & & $53.8^{* * *}$ & $206.0^{* * *}$ & & $206.0^{* * *}$ & $118.7^{* * *}$ & & $118.7^{* * *}$ \\
\hline \multicolumn{10}{|c|}{ Number of living children } \\
\hline None & 69.0 & 56.6 & 59.7 & 52.7 & 43.5 & 45.8 & 42.0 & 36.5 & 37.8 \\
\hline $1-2$ children & 67.8 & 55.4 & 67.1 & 49.8 & 49.9 & 49.8 & 39.5 & 41.0 & 39.6 \\
\hline
\end{tabular}


Table 2 Percent distribution of women who agreed that a husband is justified for beating his wife by marital status according to individual characteristics, 2003, 2008, and 2013 Nigeria Demographic and Health Survey (Continued)

\begin{tabular}{|c|c|c|c|c|c|c|c|c|c|}
\hline $3-4$ children & 66.2 & $100.0+$ & 66.3 & 49.6 & 50.0 & 49.6 & 39.5 & 48.2 & 39.5 \\
\hline $\begin{array}{l}5 \text { children } \\
\text { and above }\end{array}$ & 66.8 & $0.0+$ & 66.8 & 53.6 & 75.0 & 53.7 & 42.4 & 40.0 & 42.4 \\
\hline$x^{2}=$ test & 2.0 & 2.9 & $37.3^{* * *}$ & $33.9^{* * *}$ & $11.6^{* * *}$ & $104.6^{* * *}$ & $22.9^{* * *}$ & 6.9 & $43.9^{* * *}$ \\
\hline \multicolumn{10}{|c|}{ Women's autonomy (decision-making process) } \\
\hline $\begin{array}{l}\text { Participated } \\
\text { or involved }\end{array}$ & 60.6 & 47.8 & 58.4 & 49.2 & NA & 49.2 & 35.9 & NA & 35.9 \\
\hline $\begin{array}{l}\quad \text { Not } \\
\text { participated or } \\
\text { involved }\end{array}$ & 74.1 & 60.0 & 69.0 & 53.6 & & 49.6 & 45.3 & & 41.8 \\
\hline$x^{2}=$ test & $75.1^{* * *}$ & $25.6^{* * *}$ & $48.6^{* * *}$ & $51.4^{* * *}$ & & 0.5 & $264.5^{* * *}$ & & $135.0^{* * *}$ \\
\hline \multicolumn{10}{|l|}{ Place of residence } \\
\hline Urban & 61.2 & 55.4 & 59.3 & 40.0 & 34.4 & 38.1 & 30.3 & 31.0 & 30.5 \\
\hline Rural & 70.8 & 57.7 & 67.7 & 55.4 & 51.1 & 54.6 & 46.2 & 43.7 & 45.7 \\
\hline$x^{2}=$ test & $54.0^{* * *}$ & 1.0 & $55.9^{* * *}$ & $486.8^{* * *}$ & $223.6^{* * *}$ & $777.7^{* * *}$ & $700.3^{* * *}$ & $168.8^{* * *}$ & $901.8^{* * *}$ \\
\hline \multicolumn{10}{|l|}{ Geopolitical zone } \\
\hline North-Central & 54.2 & 56.5 & 54.8 & 49.3 & 44.1 & 48.0 & 36.9 & 35.7 & 36.6 \\
\hline Northeast & 92.7 & 88.5 & 92.1 & 54.1 & 56.7 & 54.4 & 61.8 & 51.2 & 60.1 \\
\hline Northwest & 76.1 & 65.7 & 75.1 & 61.8 & 46.0 & 60.7 & 38.4 & 28.3 & 37.3 \\
\hline Southeast & 32.7 & 42.1 & 37.2 & 51.3 & 48.7 & 50.2 & 43.1 & 41.8 & 42.6 \\
\hline South-South & 62.6 & 62.9 & 62.7 & 45.9 & 48.1 & 46.8 & 36.5 & 39.7 & 37.7 \\
\hline Southwest & 50.7 & 50.3 & 50.6 & 31.9 & 27.8 & 30.5 & 22.2 & 26.3 & 23.4 \\
\hline$x^{2}=$ test & $879.4^{* * *}$ & $146.6^{* * *}$ & $1100.0^{* * *}$ & $865.0^{* * *}$ & $258.9 * * *$ & $1200.0^{* * *}$ & $1700.0^{* * *}$ & $240.2^{* * *}$ & $1900.0^{* * *}$ \\
\hline \multicolumn{10}{|c|}{ Region of residence } \\
\hline Northern & 76.1 & 67.7 & 74.8 & 55.9 & 47.9 & 54.7 & 45.0 & 37.8 & 43.8 \\
\hline Southern & 48.6 & 50.9 & 49.6 & 41.8 & 41.5 & 41.7 & 32.6 & 36.3 & 33.9 \\
\hline$x^{2}=$ test & $414.7^{* * *}$ & $53.7^{* * *}$ & $510.4^{* * *}$ & $449.1^{* * *}$ & $31.3^{* * *}$ & $542.6^{* * *}$ & $430.6^{* * *}$ & 2.5 & $387.5^{* * *}$ \\
\hline \multicolumn{10}{|l|}{ Ethnic affiliation } \\
\hline Hausa/Fulani & 80.0 & 75.9 & 79.7 & 61.2 & 53.4 & 60.8 & 44.7 & 33.2 & 43.5 \\
\hline lgbo & 37.4 & 44.8 & 40.8 & 46.1 & 44.9 & 45.6 & 38.6 & 38.9 & 38.7 \\
\hline Yoruba & 44.4 & 48.1 & 46.0 & 31.6 & 29.5 & 30.9 & 20.3 & 24.1 & 21.5 \\
\hline $\begin{array}{l}\text { Northern } \\
\text { minorities }\end{array}$ & 74.7 & 68.1 & 73.1 & 57.2 & 56.4 & 57.1 & 48.2 & 44.5 & 47.3 \\
\hline $\begin{array}{l}\text { Southern } \\
\text { minorities }\end{array}$ & 64.9 & 61.2 & 63.2 & 43.7 & 45.8 & 44.5 & 36.2 & 38.9 & 37.2 \\
\hline $\begin{array}{l}\text { Others } \\
\text { including } \\
\text { foreigners }\end{array}$ & 71.7 & 66.3 & 69.9 & 49.0 & 47.8 & 48.7 & 46.0 & 51.8 & 47.5 \\
\hline$x^{2}=$ test & $643.3^{* * *}$ & $101.4^{* * *}$ & $781.5^{* * *}$ & $938.1^{* * *}$ & $194.7^{* * *}$ & $1200.0^{* * *}$ & $955.2^{* * *}$ & $212.0^{* * *}$ & $1100.0^{* * *}$ \\
\hline \multicolumn{10}{|c|}{ Frequency of listening to radio } \\
\hline $\begin{array}{l}\text { Never or less } \\
\text { than once a } \\
\text { week }\end{array}$ & 70.9 & 62.3 & 68.8 & 54.9 & 47.9 & 53.6 & 45.0 & 40.8 & 44.1 \\
\hline $\begin{array}{l}\text { At least once } \\
\text { a week }\end{array}$ & 64.3 & 53.3 & 61.0 & 46.9 & 41.4 & 45.3 & 32.8 & 32.1 & 32.6 \\
\hline$x^{2}=$ test & $27.0^{* * *}$ & $15.9^{* * *}$ & $49.7^{* * *}$ & $158.7^{* * *}$ & $33.1^{* * *}$ & $226.2^{* * *}$ & $416.3^{* * *}$ & $79.3^{* * *}$ & $509.1^{* * *}$ \\
\hline
\end{tabular}

Frequency of watching television 
Table 2 Percent distribution of women who agreed that a husband is justified for beating his wife by marital status according to individual characteristics, 2003, 2008, and 2013 Nigeria Demographic and Health Survey (Continued)

\begin{tabular}{|c|c|c|c|c|c|c|c|c|c|}
\hline $\begin{array}{l}\text { Never or less } \\
\text { than once a } \\
\text { week }\end{array}$ & 71.1 & 59.6 & 68.8 & 56.1 & 50.6 & 55.2 & 44.8 & 40.8 & 44.0 \\
\hline $\begin{array}{l}\text { At least once } \\
\text { a week }\end{array}$ & 57.1 & 53.8 & 55.8 & 39.1 & 38.6 & 38.9 & 31.2 & 33.1 & 31.9 \\
\hline$x^{2}=$ test & $98.4^{* * *}$ & $7.1^{* * *}$ & $127.2^{* * *}$ & $602.5^{* * *}$ & $115.3^{* * *}$ & $807.3^{* * *}$ & $470.5^{* * *}$ & $62.2^{* * *}$ & $546.9^{* * *}$ \\
\hline \multicolumn{10}{|c|}{ Frequency of reading newspaper or magazine } \\
\hline $\begin{array}{l}\text { Never or less } \\
\text { than once a } \\
\text { week }\end{array}$ & 69.1 & 59.1 & 66.6 & 52.8 & 46.7 & 51.5 & 41.5 & 38.1 & 40.7 \\
\hline $\begin{array}{l}\text { At least once } \\
\text { a week }\end{array}$ & 46.5 & 48.2 & 47.4 & 28.2 & 33.4 & 30.8 & 27.1 & 30.8 & 28.8 \\
\hline$x^{2}=$ test & $94.6^{* * *}$ & $17.5^{* * *}$ & $130.6^{* * *}$ & $393.7^{* * *}$ & $95.0^{* * *}$ & $529.7^{* * *}$ & $161.0^{* * *}$ & $31.8^{* * *}$ & $198.9^{* * *}$ \\
\hline
\end{tabular}

In Table 2, a chi-square test identified the following factors as having a significant association $(p<0.05)$ with women reporting that wife-beating is justified for at least one reason (consistent across each of the three survey years): (a) respondents' age, (b) type of union, (c) educational status, (d) wealth index, (e) exposure to media (listening to the radio, watching television, and reading newspapers/magazines), (f) place of residence (urban versus rural), (g) region, (h) ethnicity, (i) religious affiliation, (j) spousal age difference, $(\mathrm{k})$ autonomy in household decision-making, and (l) number of living children. The analysis reveals that the percentage of women reporting that wife-beating is justified also decreased significantly $(p<0.05)$ across the years for all subgroups of the study population. The patterns and trends are similar for ever-married, never-married, and all women in the three survey waves.

The multivariate models in Table 3 show the odds ratios estimating the likelihood that female respondents would accept that husbands are justified in hitting or beating their spouse under at least one circumstance. Models were estimated for ever-married, never-married, and all women, using pooled data from the 2003, 2008, to 2013 NDHS. These odds ratios from the logistic regression show the net effect of personal attributes on women's perceptions of domestic violence, specifically wife-beating. The results of the multivariate model for all women clearly reveal that the estimated odds of women agreeing that husbands are justified in beating their wives were lower in 2008 and 2013 than in 2003. The patterns of women accepting wife-beating are similar in all three models in Table 3 for the survey years. After controlling for the influence of year, the model shows that the likelihood of supporting wife-beating decreased with age among ever-married women $(p<0.001)$. The results also show that the likelihood of women accepting men's right to beat their wives increased with number of living children among ever-married women $(p<0.003)$.

The analysis further reveals that (a) education, (b) religious affiliation, (c) ethnicity, (d) place of residence, (e) region, (f) exposure to mass media, (g) household wealth quintile, and (h) female empowerment, as measured by participation in household decision-making, are significant predictors of women agreeing that husbands have the right to beat their spouses in the multivariate model for all women. 
Table 3 Multivariate odds ratio of assessing demographic and socioeconomic characteristics on agreement with wife-beating by husbands among Nigerian women, 2003, 2008, and 2013 Nigeria Demographic and Health Survey

\begin{tabular}{|c|c|c|c|}
\hline \multirow[t]{2}{*}{ Variables } & \multirow{2}{*}{$\begin{array}{l}\text { Ever-married } \\
\text { OR (SE) } \\
5.68^{* * *}(.469)\end{array}$} & \multirow{2}{*}{$\begin{array}{l}\text { Never-married } \\
\text { OR (SE) } \\
1.57^{*}(.299)\end{array}$} & \multirow{2}{*}{$\begin{array}{l}\text { All-women } \\
\text { OR (SE) } \\
4.50^{* * *}(.320)\end{array}$} \\
\hline & & & \\
\hline \multicolumn{4}{|l|}{ Year } \\
\hline 2003 (rc) & 1.00 & 1.00 & 1.00 \\
\hline 2008 & $0.41^{* * *}(.017)$ & $0.41^{* * *}(.036)$ & $0.43^{* * *}(.015)$ \\
\hline 2013 & $0.26^{* * *}(.011)$ & $0.35^{* * *}(.031)$ & $0.29^{* * *}(.010)$ \\
\hline Age & $0.99^{* * *}(.001)$ & $0.99^{* * *}(.005)$ & $0.99 * * *(.001)$ \\
\hline Number of living children & $1.02^{* * *}(.006)$ & $1.15^{* *}(.062)$ & $1.03^{* * *}(.007)$ \\
\hline \multicolumn{4}{|l|}{ Highest level of education } \\
\hline None (rc) & 1.00 & 1.00 & 1.00 \\
\hline Primary & 1.05(.032) & $1.26^{*}(.130)$ & $1.01(.028)$ \\
\hline Secondary & $0.83^{* * *}(.030)$ & 1.19(.113) & $0.81^{* * *}(.025)$ \\
\hline Postsecondary & $0.49^{* * *}(.030)$ & 0.77(.091) & $0.50^{* * *}(.025)$ \\
\hline \multicolumn{4}{|l|}{ Religious affiliation } \\
\hline Catholic (rc) & 1.00 & 1.00 & 1.00 \\
\hline Other Christians & $0.82^{* * *}(.034)$ & $0.81^{* * *}(.045)$ & $0.82^{* * *}(.027)$ \\
\hline Muslim & $0.85^{* * *}(.042)$ & $0.81^{* * *}(.065)$ & $0.84^{* * *}(.030)$ \\
\hline Others & $1.23^{* *}(.095)$ & $1.22(.291)$ & $1.21^{* * *}(.087)$ \\
\hline \multicolumn{4}{|l|}{ Wealth quintile } \\
\hline First (rc) & 1.00 & 1.00 & 1.00 \\
\hline Second & $1.10^{* * *}(.032)$ & $1.15(.098)$ & $1.11^{* * *}(.030)$ \\
\hline Third & 1.04(.034) & 1.14(.096) & $1.04(.031)$ \\
\hline Fourth & $0.79^{* * *}(.032)$ & $0.80^{* * *}(.070)$ & $0.78^{* * *}(.027)$ \\
\hline Fifth & $0.51^{* * *}(.036)$ & $0.49^{* * *}(.047)$ & $0.50^{* * *}(.022)$ \\
\hline \multicolumn{4}{|c|}{ Women's autonomy (decision-making process) } \\
\hline Not participated or involved (rc) & 1.00 & 1.00 & 1.00 \\
\hline Participated or involved & 1.04(.23) & $0.72 *(.107)$ & $1.07^{* * *}(.021)$ \\
\hline \multicolumn{4}{|l|}{ Place of residence } \\
\hline Rural (rc) & 1.00 & 1.00 & 1.00 \\
\hline Urban & $0.84^{* * *}(.023)$ & $0.93(.043)$ & $0.85^{* * *}(.020)$ \\
\hline \multicolumn{4}{|l|}{ Geopolitical zone } \\
\hline North-Central (rc) & 1.00 & 1.00 & 1.00 \\
\hline Northeast & $1.38^{* * *}(.051)$ & $1.51^{* * *}(.114)$ & $1.41^{* * *}(.047)$ \\
\hline Northwest & $0.77^{* * *}(.032)$ & $0.79^{*}(.085)$ & $0.79^{* * *}(.030)$ \\
\hline Southeast & $1.52^{* * *}(.122)$ & $1.22(.145)$ & $1.40^{* * *}(.093)$ \\
\hline South-South & $1.19 * * *(.079)$ & $1.27^{*}(.129)$ & $1.23^{* * *}(.068)$ \\
\hline Southwest & $0.67^{* * *}(.034)$ & $0.66^{* * *}(.059)$ & $0.66^{* * *}(.029)$ \\
\hline \multicolumn{4}{|l|}{ Ethnic affiliation } \\
\hline Hausa/Fulani (rc) & 1.00 & 1.00 & 1.00 \\
\hline Igbo & $0.52^{* * *}(.043)$ & $1.21(.182)$ & $0.60^{* * *}(.042)$ \\
\hline Yoruba & $0.63^{* * *}(.038)$ & 1.03(.136) & $0.65^{* * *}(.034)$ \\
\hline Northern minorities & $0.77^{* * *}(.028)$ & $1.40^{* * *}(.152)$ & $0.81^{* * *}(.028)$ \\
\hline Southern minorities & $0.62^{* * *}(.046)$ & 1.25(.182) & $0.67^{* * *}(.043)$ \\
\hline
\end{tabular}


Table 3 Multivariate odds ratio of assessing demographic and socioeconomic characteristics on agreement with wife-beating by husbands among Nigerian women, 2003, 2008, and 2013 Nigeria Demographic and Health Survey (Continued)

\begin{tabular}{llll}
\hline Others including foreigners & $0.75^{* * *}(.053)$ & $1.64^{* * *}(.266)$ & $0.82^{* * *}(.053)$ \\
$\begin{array}{l}\text { Frequency of listening to radio } \\
\text { Never or less than once a week }(\mathrm{rc})\end{array}$ & 1.00 & 1.00 & 1.00 \\
$\quad$ At least once a week & $0.97(.023)$ & $1.04(.047)$ & $0.99(.021)$ \\
Frequency of watching television & & & 1.00 \\
$\quad$ Never or less than once a week (rc) & 1.00 & 1.00 & $1.09^{* * *}(.029)$ \\
At least once a week & $1.11^{* * *}(.035)$ & $1.06(.053)$ & $-46,833.063^{* * *}$ \\
-2 log likelihood & $-36,369.565^{* * *}$ & $-10,281.732^{* * *}$ & \\
\hline
\end{tabular}

$r c$ reference category

${ }^{*} p<0.05 ;{ }^{* *} p<0.01 ;{ }^{* * *} p<0.001$

\section{Ever-married women}

Education: The analysis shows that education is inversely associated with women's support for wife-beating. Ever-married women with secondary and post-secondary education are less likely (odds ratios of 0.83 and 0.49 , respectively) to justify wifebeating under any circumstances than women with no formal education. By contrast, ever-married women with primary education are more likely (odds ratio of 1.05) to justify wife-beating relative to those with no formal education.

Household wealth index: The model shows that ever-married women in households classified in the fourth and fifth quintiles have odds ratios of 0.79 and 0.51 , respectively, of justifying wife-beating as compared to their counterparts in the first quintile of the wealth index $(p<0.0001)$. However, women in the second and third quintiles of the household wealth index have odds ratios of 1.10 and 1.04, respectively, of justifying wife-beating compared to the reference category. This association was significant for the second quintile but not for the third quintile (see Table 3). The analysis reveals that ever-married women who are urban dwellers are less likely to justify wife-beating relative to their rural counterparts.

Ethnicity: The analysis reveals that an ever-married woman's likelihood of accepting wife-beating varied significantly among different ethnic groups in Nigeria. For instance, women with an ethnic affiliation with the Igbo, Yoruba, Northern minority, Southern minority, and other tribes are less likely to accept wife-beating as compared with women from the Hausa/Fulani ethnic group. The odds ratio that women who are from the Igbo and Yoruba ethnic group accept wife-beating are 0.52 and $0.63(p<0.0001)$, respectively, relative to women from the Hausa/Fulani ethnic groups. Place of residence: Ever-married women who live in the Northeast, Southeast, and South-South have higher odds of justifying wife-beating relative to women who reside in North-Central; women living in the Northwest and Southwest regions have lower odds of reporting that wife-beating is justified for any reason. Specifically, women living in the Northeast, Southeast, and South-South have odds ratios of about 1.38, 1.52 , and 1.19, respectively, of justifying wife-beating relative to their counterparts residing in North-Central. Surprisingly, ever-married women living in the Northwest are significantly less likely to justify wife-beating in any situation as compared to their counterparts from North-Central. 
Religion: The overwhelming majority of Nigerians are either Muslim and Christian, and others are either traditionalists or have no religious affiliation. All of these religions incorporate beliefs and practices that, along with cultures, vary greatly in their impact on women. The analysis reveals that religion is consistently associated with the odds of women reporting that wife-beating is justified. Specifically, evermarried women living in Muslim and Protestant households have odds ratios of 0.85 and 0.82 , respectively, of reporting that wife-beating is ever justified, relative to their counterparts living in Catholic households. This implies that ever-married women living in Muslim and other Christian households, as compared with women in Catholic households, have lower odds of reporting that wife-beating is justified, while women who are either traditionalists or have no religious affiliation have higher odds of supporting wife-beating.

Female empowerment: As shown in Table 3, the associations between women's participation in household decision-making and support for wife-beating was statistically significant after adjusting for respondents' other sociodemographic attributes. Surprisingly, ever-married women who participated or were involved in household decisions are 1.04 times more likely to support wife-beating compared with those who reported no involvement in household decision-making.

Exposure to mass media: Women who reported listening to the radio are less likely to support wife-beating than those who do not listen to the radio. However, those who watch television are more likely to justify wife-beating as compared to those who do not watch television.

\section{Never-married women}

Predictors of acceptance of wife-beating among never-married are similar to the predictors found among ever-married women, though the significant associations were stronger in ever-married after, controlling for the covariate. In addition, the odds of nevermarried women justifying wife-beating seem higher compared with the odds ratios for ever-married women. The multivariate model in Table 3 for never-married women shows that the odds of never-married women justifying wife-beating were lower in 2008 and 2013 relative to 2003. After controlling for the influence of the survey year, the model shows that justification for wife-beating decreased with age for single women $(p<0.001)$. Never-married women who had primary and post-secondary education were less likely to justify wife-beating than were those with no formal education. In addition, non-Catholic Christians and Muslims were less likely than Catholic Christians to justify wife-beating, and women who were involved in household decision-making were less likely to support wife-beating than were those who were never involved in such decision-making.

The multivariate model for the never-married women likewise shows that those in the second and third quintiles $(p<0.05)$ of the wealth index were more likely to support wife abuse than those in the first quintile. However, women in the fourth and fifth quintiles were less likely to support wife-beating for any reason, as compared to those in the first quintile, though the odds ratio diminished significantly for women in the fourth quintile. Never-married women who are urban dwellers were less likely than their rural counterparts agree that wife-beating is justified. Although ethnic affiliation was revealed to have some influence on attitudes towards wife abuse among single 
women, the odds ratio was not statistically significant. A rather surprising finding was that single women from other ethnic groups (except for the Yourbas) had a higher odds ratio of supporting wife-beating than single women from the Hausa/Fulani ethnic group. Single women in the Northeast, Southeast, and South-South regions were more likely to justify wife-beating than were their North-Central counterparts. Although single women from the Southeast were more likely to support husbands beating their wives, this odds ratio was not statistically significant. The frequency of listening to the radio did not significantly affect the likelihood that single women would support wife-beating.

These findings underscore that women's attitudes towards wife-beating have multiple determinants, with ever-married and never-married women in separate models. The findings for all women were similar to those derived by considering ever-married and never-married women separately. These findings revealed that (a) age, (b) number of living children, (c) level of education, (d) religion, (e) household wealth index, (f) place of residence (i.e., urban versus rural), (g) region of residence, (h) ethnicity, and (i) frequency of watching television significantly affected the likelihood that a woman would support wife-beating. However, when the data are not separated by ever-married and never-married status, women's autonomy, frequency of listening to the radio, and marital status did not significantly affect the likelihood that a woman would support wife-beating.

\section{Discussion}

Over the past 10 years, the proportion of Nigerian women who support or accept wifebeating as a norm has declined, although findings from this study show that a sizeable percentage of Nigerian women still justify wife-beating for minor reasons, particularly burning food during preparation. Other reasons for which the women agreed that beating could be justified are (a) refusing to have sex with her husband, (b) arguing with her husband, (c) going out without telling her husband, and (d) neglecting the children. These are associated with expected traditional gender roles.

\section{Diminished support for domestic violence among Nigerian women}

The analysis revealed that in 2003, $62.4 \%$ of women surveyed perceived that husbands are justified in beating their wives for at least one of the reasons mentioned in the survey; this percentage declined in the subsequent surveys to $45.7 \%$ in 2008 and to $37.1 \%$ in 2013. Although the study focused on the acceptance of wife-beating among women, the consistency of the results with those of studies examining men's attitudes towards wife-beating in 18 countries in Africa, Asia, Latin America, and the Caribbean (MacQuarrie et al. 2015) suggests that the current findings are relevant to broader issues of gender dynamics and normative values.

Patriarchal beliefs still prevail, remaining an important factor for the perpetuation of gender-based and especially domestic violence in sub-Saharan Africa, including in Nigeria. However, this analysis reveals evidence of a cultural shift, with a declining proportion of women believing that wife-beating is justified. Anecdotal evidence of this cultural shift also abounds. For instance, wives of political officeholders, including the spouses of the President and State Governors, have launched projects to address gender-based violence and support gender equality in Nigeria. These interventions seek 
to create and advocate for female empowerment at several levels: helping women play more significant roles in management and the professions, gain political influence within elected and appointed positions, and participate in household decision-making.

The findings of this study offer further evidence that in any society, normative values, including norms surrounding violence against women, are dynamic. In this regard, Nigeria is no exception. The study analysis shows that ever-married women support wife-beating more than do their never-married counterparts. This may be explained in the context of the institution of marriage in Nigeria, where the man is the head of the household and women who are married are strongly committed to maintaining the relationship regardless of the circumstances. The percentage of women justifying husbands' right to beat their spouses has been declining in the past 10 years across segments of society.

The observed relationship between a woman justifying wife-beating and marital status is expected. It may be that ever-married women, having experienced domestic violence firsthand, might provide a response to the DHS that fits in with community attitudes. By contrast, never-married women may have better knowledge about rights, gender equality, and female empowerment, which could encourage this group of women to challenge traditional norms that require women to be submissive to their husbands. Never-married women are more likely to be educated than their ever-married counterparts.

The study results show a negative relationship between education and household wealth quintile and women's acceptance of wife-beating. The results indicate that patterns of support for wife-beating decline with increasing level of education and increasing household wealth quintile. The findings correlate with MacQuarrie et al. (2015), who showed that men's acceptance of wife-beating declines with increasing levels of education and household wealth quintile. A plausible explanation for these findings is that educated women and those living in households in a higher wealth quintile are likely to be in (or potentially be in) a more modern and egalitarian relationship than uneducated women and women at the lowest wealth quintile.

The analysis reveals that even given the general decline in support for wife-battery, older Nigerian women are less likely to support the practice than are younger women. Women's acceptance of wife-beating declined with increasing age for both evermarried and never-married categories. This decline may be due to women's better understanding of dyadic relationships and power play within the marital union as they grow older. Older women may also be more likely than younger women to have a good understanding of the norms and values that protect women within marriage or prevent men from being aggressive. For instance, most Nigerian cultures have mechanisms for rebuking men who are aggressive in formal or informal marital relationships. Younger married or never-married women may have been exposed to more recent messages that promote women's agency; they may thus hinge their relationships on equality, which is a core value of women's advocacy.

\section{Geographic trends}

Regional variations in attitudes towards wife-beating suggest that though violence against women in Nigeria is universal, it occurs in different forms and degrees from region to region. These results corroborate those of a study done in Zimbabwe (Hindin 2003), and 
these heterogeneous tendencies may be attributed to variability in ethnic or cultural norms and socioeconomic differences. For instance, the North-Central and South-South regions tend to be multicultural and exhibit variability in educational levels among different ethnic groups, while the Northeast and Northwest regions are more rural, dominated by specific cultural and traditional norms that are seen as vital. Exploring these disparities may require a model that captures multilevel, random, or contextual effects, such as ethnicity, level of community development, or other regional variables. Such models would be an interesting and worthwhile extension to the regression model used in this analysis.

Overall, this study reveals a declining trend in women's acceptance of wife-beating, except in the Southeast region, an Igbo-dominated region where acceptance increased. This may be due to the Igbo tradition of payment of expensive bride's wealth by the husband's family to the wife's, which supports the husband's dominance and reflects a traditional gender hierarchy in which men are considered superior to women. The bride's wealth payment among Igbo speakers may promote violence against women, since it symbolizes "loss of rights" by the bride and "transfer of rights" to the groom. Past study has revealed that Igbo women experienced more domestic violence as compared with their Yoruba and Hausa/Fulani counterparts (Tenkorang et al. 2013). Experience of wife-battery in this region may explain the increased support for wifebeating among Igbo women; expressing support for this practice during the survey may be a way of providing a response that aligns with community norms.

\section{Religion and support for domestic violence}

Religion, as an indicator of social control, appears to exert a different effect on married versus never-married women. Its effect on the dynamics of normative values, including gender-related values such as support for wife-beating, is changing over time (Norris and Inglehart 2002). The study found that in 2013, Protestant women were less likely than Catholic women to support wife-battery-a finding that has been observed elsewhere (for example in Burkina Faso: see Pambe et al. 2014). The liberal gospel and doctrines professed by Protestants may explain this association.

It should be noted that women who are Christian, whether Catholics or Protestants, are less likely than Muslim women to hold positive attitudes towards wife-beating (Obeid et al. 2010). The position of Islamic doctrine regarding violent acts against wives has mixed interpretations, partly due to the multiple factors that determine a women's status and how these factors relate to patriarchal ideologies. However, the study's findings on Muslim women's views about wife-beating may be explained by Islam's patriarchal position on women's submission to their husbands. The effect of religion on violence against women could be interpreted as having the same effect as does culture. Beliefs and norms do change over time, and religion has an influence on both, which in turn have an impact on gender-based violence (Norris and Inglehart 2002; Rashid et al. 2014).

These results suggest a disparity in the attitudes towards wife-beating between Christians and Muslims in Nigeria. The reason for the North/South disparity cannot be fully determined from this analysis. Potential explanations might include the influence of religious traditions, teachings, doctrines, religious communities, and institutions that convey values and belief systems to their members. More research is necessary to determine the underlying causes of the difference. 
Regardless, understanding how religious groups in Nigeria relate to gender-based violence will help guide policies and programs to reduce the burden and consequences of domestic violence against women. In addition, adherents to particular religions often receive direct support or counseling through relationships with religious leaders, whose guidance could influence support for wife-beating. Religious texts and teachings can serve as resources to shape perceived attitudes towards abuse and to manage episodes of abuse. Yet religion can also be misused to excuse or condone abusive behavior. In the context of violence against women, religious teachings and communities will always play a role and may never be neutral.

\section{Limitations and further research}

This study has limitations, some of which are inherent in the DHS datasets used and the quantitative approach, which enables only certain types of exploration of attitudes. Some of the variables used may raise selection bias; endogenous and appropriate techniques are required to model the relationships that may exist between the response variable and the explanatory variables. For instance, a mixed regression model that incorporates random effects may be appropriate. Random effects may capture some of the unobserved and unmeasured population effects that influence normative values. The use of a multilevel modelling technique would account for the hierarchical structure of the data, adjusting for estimated coefficients and other cluster-level sources of unobserved heterogeneity (variance) that may be associated with attitudes or perceptions towards justification of wife-beating or of domestic violence.

In addition to the quantitative approaches mentioned above, there is a need to collect qualitative data to explain the underlying context of the continuing acceptance of wifebeating among Nigeria women.

Traditional attitudes and behavior relative to gender appear to be changing in Nigeria, and this study suggests a steady decline in women's acceptance of genderbased violence. Study findings reveal that demographic and socioeconomic characteristics have important and similar effects on cultural values, especially gender norms, that affect the attitudes of Nigerian women towards wife-beating-confirming the findings of other researchers working within the same theoretical framework (Hindin 2003; Oyediran and Isiugo-Abanihe 2005). These findings should inform the strategies of both policymakers and advocates for women's empowerment.

The traditional gender attitudes and behavior may be changing in Nigeria. This is the first study to document trends in Nigerian women's acceptance of gender-based violence at home. Acceptance has declined overtime.

\section{Conclusions}

Nigerian society appears to be in a period of social change, as reflected in emerging patterns of attitudes towards violence against women. Analysis of findings from three NDHS studies show a decreasing proportion of women agreeing that their husbands have a right to hit or beat them. This can best be described as a cultural shift from women being submissive to male dominance to a modern attitude that promotes individual rights and gender equality. 
If patriarchal beliefs are viewed as important factors behind domestic violence in Nigeria, policymakers, advocates of female empowerment, researchers, and social workers should be more concerned with examining the factors associated with these beliefs. This study examined some of the socioeconomic factors behind women's support for wife-beating. The findings indicate that higher education and household wealth, along with several other factors, influence respondents' perceptions of husbands' justifications for wife-beating. The more educated women are, the less likely they are to justify wifebeating. Similarly, with higher household socioeconomic status, women become less likely to believe that only men have the power to decide on their behalf. This is an indication for Nigerian policymakers to make available more educational and career opportunities for both men and women, giving them equal power within their families.

This study also shows that demographic and sociocultural factors associated with believing that wife-beating is justified-particularly religion, region of residence, and place of residence (urban versus rural)-have had similar effects over the years. The role played by these factors is important and should inform policies aimed at addressing gender-based violence, including domestic violence.

This study shows evidence of a positive cultural shift: a diminishing acceptance of violence towards women in the household. Notwithstanding this evidence, and the significant attention given to the topic of domestic violence in Nigeria in recent years, the work is not complete. As of the third DHS study, in 2013, 40\% of women still accepted wife-beating. Anecdotal evidence suggests that gender-based violence will continue to be an important challenge with colossal individual and societal consequences. Therefore, there is a significant need for further study, and particularly qualitative data, to clarify the contextual factors that may facilitate and entrench normative values and practices that constantly expose women to domestic violence.

\footnotetext{
Acknowledgements

Sincere appreciation goes to the ICF International and the National Population Commission, Abuja, Nigeria, for granting the permission to use the datasets from the Nigeria Demographic and Health Survey. I would like to thank Dr. Gbenga Ishola, Senior Regional M\&E Advisor of Jhpiego office in Nigeria, and Dr. Akinrinola S. Bankole, Director of International Research of the Guttmacher Institute, New York, USA, for a thoughtful review of an earlier draft. The editing work by Stephanie Joyce which helped make the paper more concise is highly appreciated. The views expressed are solely those of the author and do not represent the view of his institution.
}

Competing interests

The authors declare that they have no competing interests.

Received: 4 February 2016 Accepted: 22 November 2016

Published online: 06 December 2016

References

Bukatko, D., \& Daehler, M. W. (2001). Child development: a thematic approach (4th ed.). Boston: Houghton Mifflin Company.

Burazeri, G., Roshi, E., Jewkes, R., Jordan, S., Bjegovic, V., \& Laaser, U. (2005). Factors associated with spousal physical violence in Albania: cross-sectional study. British Medical Journal, 331(7510), 197-201.

Campbell, J. (2002). The health consequences of intimate partner violence. Lancet, 359, 1509-1514.

Diop-Sidibe, N., Campbell, J. C., \& Becker, S. (2006). Domestic violence against women in Egypt: wife beating and health outcomes. Social Science and Medicine, 62(5), 1260-1277.

Douki, S., Nacef, F., Belhadj, A., Bouasker, A., \& Ghachem, R. (2003). Violence against women in Arab and Islamic countries. Archives of Women's Mental Health, 6(3), 165-171.

Ellsberg, M. C., Pena, R., Herrera, A., Liljestrand, J., \& Winkvist, A. (1999). Wife abuse among women of childbearing age in Nicaragua. American Journal of Public Health, 89(2), 241-244.

Garcia-Moreno, C., Jansen, H. A., Ellsberg, M., Heise, L., \& Watts, C. H. (2006). Prevalence of intimate partner violence: findings from the WHO multi-country study on women's health and domestic violence. Lancet, 368, 1260-1269. Heise, L. (1993). Violence against women: the hidden health burden. World Health Statistics Quarterly, 46, 78-85. Hindin, M. J. (2003). Understanding women's attitudes towards wife beating in Zimbabwe. Bulletin of the World Health Organization, 81(7), 501-508. 
Hindin, M. J., Kishor, S., \& Ansara, D. L. (2008). Intimate partner violence and couples in 10 DHS countries: predictors and health outcomes. DHS analytical studies no. 18. Calverton: Macro Internationa.

llika, A. L., Okonkwo, P. I., \& Adogu, P. (2002). Intimate partner violence among women of childbearing age in a primary health care centre in Nigeria. African Journal of Reproductive Health, 6(3), 53-58.

Khan, M. E., \& Aeron, A. (2006). Prevalence, nature, and determinants of violence against married women in Bangladesh. Journal of Family Welfare, 52(Special Issue), 33-51.

Khawaja, M., \& Barazi, R. (2005). Prevalence of wife beating in Jordanian refugee camps: reports by men and women. Journal of Epidemiology and Community Health, 59(10), 840-841.

Khawaja, M., Linos, N., \& El-Roueiheb, Z. (2008). Attitudes of men and women towards wife beating: findings from Palestinian refugee camps in Jordan. Journal of Family Violence, 23, 311-323.

Khawaja, M., \& Twetel-Salem, M. (2004). Agreement between husband and wife reports of domestic violence: evidence from poor refugee communities in Lebanon. International Journal of Epidemiology, 33, 526-533.

Kim, J., \& Motsei, M. (2002). "Women enjoy punishment": attitudes and experiences of gender-based violence among PHC nurses in rural South Africa. Social Science and Medicine, 54, 1243-1254.

Kimani, M. (2007). Taking on violence against women in Africa: international norms, local activism start to alter laws, attitudes. Africa Renewal, 21(2), 4.

Kishor, S., \& Johnson, K. (2004). Profiling domestic violence: a multi-country study. Calverton: ORC Macro.

Koenig, M. A., Lutalo, T., Zhao, F., Nalugoda, F., Wabwire-Mangen, F., Kiwanuka, N., Wagman, J., Serwadda, D., Wawer, M., \& Gray, R. (2003). Domestic violence in Rakai, Uganda: evidence from a community-based survey. Bulletin of the World Health Organization, 81(1), 53-60.

Krug, E. G., Dahlberg, L. L., Mercy, J. A., Zwi, A. B., \& Lozano, R. (2002). World report on violence and health. Geneva: World Health Organization

Lawoko, S. (2006). Factors associated with attitudes toward intimate partner violence: a study of women in Zambia. Violence and Victims, 21(5), 645-656.

Lawoko, S. (2008). Predictors of attitudes toward intimate partner violence: a comparative study of men in Zambia and Kenya. Journal of Interpersonal Violence, 23(8), 1056-1074.

Linos, N., Khawaja, M., \& Al-Nsour, M. (2010). Women's autonomy and support for wife beating: findings from a population-based survey in Jordan. Violence and Victims, 25(3), 409-419.

MacQuarrie, Kerry L.D., Jeffrey Edmeades, Mara Steinhaus, \& Sara K. Head (2015). Men and contraception: trends in attitudes and use. DHS analytical studies no. 49. Rockville, Maryland, USA: ICF International.

Mamunur, R., Manzur, K., Perera Nirmala, K. P., \& Arpana, S. (2014). Attitudes towards wife beating: a population-based study in Bangladesh. Violence and Gender, 1(4), 170-175. doi:10.1089/vio.2014.0015.

Mayhew, S., \& Watts, C. (2002). Global rhetoric and individual realities: linking violence against women and reproductive health. In K. Lee, K. Buse, \& S. Fustukian (Eds.), Health policy in a globalising world (pp. 159-180). Cambridge: Cambridge University Press.

Norris, P., \& Inglehart, R. (2002). Islamic culture and democracy: testing the 'clash of civilizations' thesis. Comparative Sociology, 1, 235-263.

Obeid, N., Chang, D. F., \& Ginges, J. (2010). Beliefs about wife beating: an exploratory study with Lebanese students. Violence Against Women, 16, 691-712.

Odujinrin, O. (1993). Wife battering in Nigeria. International Journal of Gynaecology and Obstetrics, 41(2), 159-164.

Ogunjuyigbe, P. O., Akinlo, A., \& Ebigbola, J. A. (2005). Violence against women: an examination of men's attitudes and perceptions about wife beating and contraceptive use. Journal of Asian and African Studies, 40, 219-229.

Okemgbo, C. N., Omideyi, A. K., \& Odimegwu, C. O. (2002). Prevalence, patterns, and correlates of domestic violence in selected Igbo communities of Imo State, Nigeria. African Journal of Reproductive Health, 6(2), 101-114.

Oyediran, K., \& Cunningham, M. (2014). Spatial patterns in domestic violence and HIV prevalence in Nigeria. Journal of Therapy and Management in HIV Infection, 2, 16-23. doi:10.12970/2309-0529.2014.02.01.3.

Oyediran, K. A., \& Isiugo-Abanihe, U. C. (2005). Perceptions of Nigerian women on domestic violence: evidence from 2003 Nigeria Demographic and Health Survey. African Journal of Reproductive Health, 9(2), 38-53.

Oyedokun, A. O. (2007): Predictors of attitudes toward wife battering among Nigerian men: evidence from Nigeria Demographic and Health Survey 2003. Journal of Multicultural, Gender and Minority Studies, 1(1).

Owoaje, E. T., \& OlaOlorun, F. M. (2012). Women at risk of physical intimate partner violence: a cross-sectional analysis of a low-income community in southwest Nigeria. African Journal of Reproductive Health, 16(1), 43-53.

Pambe, M. W., Gnoumou/Thiombiano, B., \& Kabore, I. (2014). Relationship between women's socioeconomic status and empowerment in Burkina Faso: a focus on participation in decision-making and experience of domestic violence. African Population Studies, 28(2), 1146-1156.

Pierotti, S. R. (2013). Increasing rejection of intimate partner violence: evidence of global cultural diffusion American sociological review 78(2) 240-265. http://asr.sagepub.com/content/78/2/240.full.pdf+html.

Rani, M., Bonu, S., \& Diop-Sidibe, N. (2004). An empirical investigation of attitudes towards wife-beating among men and women in seven sub-Saharan African countries. African Journal of Reproductive Health, 8(3), 116-136.

Silverman, J. G., Decker, M. R., Saggurti, N., Balaiah, D., \& Raj, A. (2008). Intimate partner violence and HIV infection among married Indian women. Journal of the American Medical Association, 300, 703-710. doi:10.1001/jama.300.6.703.

Solanke, B. L. (2014). Association between intimate partner violence and utilisation of maternal health services in Nigeria. African Population Studies, 28(2), 933-945.

Tenkorang, E. Y., Yeboah, E. H., Owusu, Y. A., \& Bannerman, R. (2013). Factors influencing domestic and marital violence against women in Ghana. Journal of Family Violence, 28(8), 771-781.

United Nations. (1995). Proceedings from The fourth world conference on women. Beijing, China, September 4-15, 1995. New York: United Nations. (Document A/CONF.177/20).

Usta, J., Farver, J. A., \& Pashayan, N. (2007). Domestic violence: the Lebanese experience. Public Health, 121(3), 208-219.

Uthman, OA. Lawoko, S and Moradi, T. (2009). Factors associated with attitudes towards intimate partner violence against women: a comparative analysis of 17 sub-Saharan countries, BMC International Health and Human Rights, 9(14). doi:10.1186/1472-698X-9-14. 
Watts, C., \& Mayhew, W. S. (2004). Reproductive health services and intimate partner violence: shaping a pragmatic response in sub-Saharan Africa. International Family Planning Perspectives, 30(4), 207-213.

Wekwete, N. N., Sanhokwe, H., Murenjekwa, W., Takavarasha, F., \& Madzingira, N. (2014). The association between spousal gender based violence and women's empowerment among currently married women aged 15-49 in Zimbabwe: evidence from the 2010-11 Zimbabwe Demographic and Health Survey. African Population Studies, 28(3), 1413-1431.

Submit your manuscript to a SpringerOpen ${ }^{\circ}$ journal and benefit from:

- Convenient online submission

- Rigorous peer review

- Immediate publication on acceptance

- Open access: articles freely available online

- High visibility within the field

- Retaining the copyright to your article

Submit your next manuscript at $>$ springeropen.com 